Review

\title{
Impact of Alternative Stabilization Strategies for the Production of PAN-Based Carbon Fibers with High Performance
}

\author{
Spyridon Soulis ${ }^{1}$, George Konstantopoulos ${ }^{1}$, Elias P. Koumoulos ${ }^{1,2}$ (D) and \\ Costas A. Charitidis ${ }^{1, *}$ \\ 1 Research Unit of Advanced, Composite, Nano-Materials and Nanotechnology (R-Nano Lab), \\ Material Science and Engineering Department, School of Chemical Engineering, National Technical \\ University of Athens, GR-15780 Zographou, Greece; sksoulis@central.ntua.gr (S.S.); \\ gkonstanto@chemeng.ntua.gr (G.K.); epk@innovation-res.eu (E.P.K.) \\ 2 Innovation in Research \& Engineering Solutions (IRES), Boulevard Edmond Machtens 79/22, \\ 1080 Brussels, Belgium \\ * Correspondence: charitidis@chemeng.ntua.gr
}

Received: 22 December 2019; Accepted: 29 April 2020; Published: 26 May 2020

\begin{abstract}
The aim of this work is to review a possible correlation of composition, thermal processing, and recent alternative stabilization technologies to the mechanical properties. The chemical microstructure of polyacrylonitrile (PAN) is discussed in detail to understand the influence in thermomechanical properties during stabilization by observing transformation from thermoplastic to ladder polymer. In addition, relevant literature data are used to understand the comonomer composition effect on mechanical properties. Technologies of direct fiber heating by irradiation have been recently involved and hold promise to enhance performance, reduce processing time and energy consumption. Carbon fiber manufacturing can provide benefits by using higher comonomer ratios, similar to textile grade or melt-spun PAN, in order to cut costs derived from an acrylonitrile precursor, without suffering in regard to mechanical properties. Energy intensive processes of stabilization and carbonization remain a challenging field of research in order to reduce both environmental impact and cost of the wide commercialization of carbon fibers $(\mathrm{CFs})$ to enable their broad application.
\end{abstract}

Keywords: carbon fibers; chemical properties; strength; mechanical properties; stabilization; irradiation

\section{Introduction}

\subsection{Carbon Fibers Overview}

Carbon fibers ( $\mathrm{CFs}$ ) are widely used as reinforcement in advanced composite materials, in aircraft construction, rocket engineering, automotive, wastewater treatment, structural supercapacitor units, smart textiles, and sports. The features of high mechanical properties, high stiffness, high electrical and thermal conductivity, almost unsurpassable thermal stability and flame retardancy, as well as ease of processability, mean that CFs are ideal to serve a wide variety of applications [1-5]. Thus, it is not surprising that the CFs market has an annual growth of about $10 \%$, mainly in the form of composites, and this trend is expected to continue in the forthcoming years [6,7]. Moreover, the CF engineering field is still fruitful for advances towards the theoretical maximum value of tensile strength of $180 \mathrm{GPa}$ derived by carbon-carbon interaction. Currently, maximum tensile strength achieved was $7 \mathrm{GPa}$ and quite recently a further increase up to $8.3 \mathrm{GPa}$ was demonstrated at the commercial level [8-10]. High performance CFs are mainly produced from cellulose, polyacrylonitrile or pitch. The relevant industry is dominated by polyacrylonitrile (PAN)-based fibers (representing almost $90 \%$ of 
the total CF production) with several companies' annual capacities exceeding 10,000 tons [11-14]. However, the high cost of the currently used technology (the combined cost of the precursors and stabilization account for 70\% of total CF synthesis cost) is restricting the applicability of this technology (15-25\$/kg CF). This demonstrates the current necessity to differentiate the processes, aiming to lower the cost below 11-15 $\$ / \mathrm{kg}$ in order to widely commercialize the CF products [15-19]. The center of interest is to manufacture CFs with tensile strength of $1.72 \mathrm{GPa}$ and modulus of $172 \mathrm{GPa}$ to meet the standards of the automotive industry [20].

Synthesis and PAN stereochemical structure conformation is critical in CF performance. Homopolymer PAN cannot be easily dissolved, due to the strong nitrile dipole interactions. Consequently, copolymerization of PAN with various monomers that increase segmental mobility, such as ester and vinyl groups, are commonly used to enhance processability and fiber spinning $[1,2,4,11,21-24]$. Rheology of the spinning dope can be improved by having a polymer with low Polydispersity Index (PDI), but is also enhanced by copolymerization with $0.5 \%-6 \%$ mol ratio of methacrylic acid (MA), acrylic acid (AA), vinyl acetate (VA) and methyl acrylamide (MAA) $[11,12,25,26]$. Furthermore, these comonomers are considered as a realistic approach to facilitate short-term reduction of CFs cost. However, replacement of acrylonitrile (AN) with a monomer such as MA or VA at a ratio of $15 \mathrm{~mol} \%$ can possibly induce fiber fusion during thermal processing [13]. Finally, after the spinning process, an additional hot drawing step is applied (either in solvent or steam-assisted), in the temperature range $90-180{ }^{\circ} \mathrm{C}$ under neutral or mild acidic conditions $(\mathrm{pH}>3.5)$, in order to improve orientation $[11,13,14,19]$.

Thermal oxidative treatment (or stabilization) is frequently regarded as the most crucial step in CF production in order to obtain high strength CFs $[15,19]$. It corresponds to $75 \%-80 \%$ of the total manufacturing duration of CFs [13]. The quality of the CF structure is determined by critical thermally influenced stereochemical rearrangements. Nitrile oligomerization/polymerization is considered the most important transformation, characterized by the intense exothermic character due to the opening of the $-\mathrm{C} \equiv \mathrm{N}$ triple bond $[27,28]$. The dissipation of the heat evolved is one of the issues to be considered during the thermal treatment. At the present time, exothermic phenomena are mediated only by the addition of acidic comonomers in $0.4-1 \mathrm{wt}$. \% mole to prevent chain scission [19], which also lowers the activation energy of stabilization $[10,11,23,27,28]$. Additionally, due to functionalities of both acrylamides and amines, stabilization progress can be significantly boosted at low content of $1 \mathrm{~mol} \%$, [15,23]. N-Isopropylacrylamide (NIPAM) and Dimethylaminopropylamine (DMPAA) are used as comonomers in order to study skin-core effect in the CFs, and monitor changes in compression strain, as well as the shear stress parallel to the preferred orientation of layer planes during carbonization (which is generated in the interface of skin and core by the different preferred orientation) [29-31]. It is worth noting that all studies of commercial high performance CFs report the existence of skin and core morphology as observed by many diverse methods such as Nanoindentation, elemental distribution analysis, Scanning and Transmission Electron Microscopy, and Synchrotron X-rays [29,32-34].

Oxidation is the second most important reaction during stabilization. The attack of oxygen radicals on already cyclized structures leads to high thermal stability, infusibility of heat treated PAN fibers, and thus carbon yield is maximized [23]. A promoting effect is evidenced on intramolecular crosslinking reactions during carbonization related to the extent of oxidation, and has an impact on forming high strength CFs. Aromatization or stabilization index of PAN fibers is often monitored through FTIR, DSC, and XRD. Many research groups have concluded that not completely stabilized fibers deliver CFs of higher strength, with total oxygen content up to $21 \%$ into the polymer backbone $[1,3,10,11,19,35-38]$. The introduction of alternative technologies to accelerate preoxidation treatment before thermal processing has been suggested. Microwave, plasma, $\mathrm{UV}$, and electron beam irradiation (EBI), or Boron doping during carbonization are the most operative techniques to serve high performance CFs by reducing stabilization duration up to $30 \mathrm{~min}$, along with reducing energy and cost demands [24].

Carbonization of PAN fibers is achieved in inert atmosphere at temperatures up to $1500{ }^{\circ} \mathrm{C}$ to produce high strength CFs with total carbon content over 92 at.\% [11]. Carbonization often is 
performed in multiple stages; precarbonization occurs in the temperature range of $450-650{ }^{\circ} \mathrm{C}$ and is connected to dehydrogenation reactions with by-products of $\mathrm{H}_{2}, \mathrm{CO}, \mathrm{CO}_{2}$, and $\mathrm{CH}_{4}$. The next step is performed in the range of $800-1500{ }^{\circ} \mathrm{C}$, with several reports documenting a radical increase of an order of magnitude in mechanical properties by comparing CFs manufactured below and over $1300{ }^{\circ} \mathrm{C}[1,29,32,39-41]$. Commonly, $\mathrm{CFs}$ of the highest strength are produced at $1500{ }^{\circ} \mathrm{C}$, since any further increase leads to a deterioration of tensile strength and a linear increase in Young Modulus. This is attributed to gradual growth in crystallite size and thickness during carbonization [8]. By the end of carbonization, the structure of the CFs is not fully graphitized and is described as turbostatic graphite $[2,3,5]$. Further heat treatment is classified as graphitization of CFs and the expected total carbon content is over 99 at.\% [11]. During this step temperature is varied above $1800{ }^{\circ} \mathrm{C}$ and up to $3000{ }^{\circ} \mathrm{C}$ in an atmosphere of argon due to the instability of nitrogen in such high temperatures. Graphitization is performed to improve orientation of basal planes and stiffness [39], but often layer orientation is random and rarely parallel to fiber axes [29]. Concerning the relative importance of each treatment, oxidative stabilization is considered as the most significant step as proved by a multitude of review papers either on CF manufacturing [2,4,5,42,43], or stabilization [1,10,35,44].

\subsection{Chemistry of PAN Precursors towards Carbon Fibers Production}

Acrylonitrile is commonly polymerized via chain reaction or free radical and anionic polymerization mechanism; the polymerization can be performed using either bulk, solution, suspension, slurry, $\gamma$-ray assisted, emulsion or solid-state techniques $[45,46]$. The synthesis of a precursor with low PDI can significantly improve the rheological behavior for fiber spinning. This feature is also enhanced by copolymerization with $0.5 \%-6 \%$ mol ratio of MA, AA, VA and MAA $[11,12,25,26]$. In this direction, solution polymerization is mainly utilized to prepare acrylic polymers that can be directly spun into fibers, using highly polar aprotic organic solvents or aqueous solutions of salts like sodium thiocyanate (NaSCN). The polymerization mechanism is similar to bulk polymerization and up to $90 \%$ conversion can be achieved within a residence time of less than $2 \mathrm{~h}$ [46]. As far as the emulsion process is concerned, a redox system is used at low temperatures, yielding a polymer with better quality as indicated by color compared to conventionally polymerized PAN. A similar qualitative result is observed for PAN copolymer of high stereochemical tacticity [28].

The overview of polymerization techniques suggests that solution polymerization is beneficial compared to other approaches, as polymerization and spinning are conducted in a single step; there is no need for separation and dissolution of PAN into a spinning dope. As a result, this technique is promising to make more efficient plants for PAN-based CFs production [4,47-49]. Still, there are challenges to be met in solution polymerization to enable successful application at a larger scale. Below saturation, AN kinetics are precisely described by the conventional models for vinyl polymerization. However, when concentration of the monomer is above $4 \mathrm{~mol} / \mathrm{L}$ in DMF or $6 \mathrm{~mol} / \mathrm{L}$ in ethylene carbonate $\left(\mathrm{EC},\left(\mathrm{CH}_{2} \mathrm{O}\right)_{2} \mathrm{CO}\right)$, then the monomer loses chemical affinity and the mixture becomes heterogeneous [47]. Moreover, apart from the kinetics of the main reactions, transfer reactions and side reactions have to be considered; these reactions lead to structural defects, chain scission, with color degradation. Two major mechanisms are identified; (i) hydrogen abstraction from AN, with a-C atom in the polymer chain forming a polymer radical, and (ii) polymerization of the nitrile group [47].

Given the high polarity of the nitrile groups, homopolymer PAN is difficult to process [50]. Itaconic acid (IA) is well-established co-monomer in PAN synthesis and has demonstrated an optimum content between 1.0 and $2.0 \mathrm{~mol} \%$ (using aqueous slurry technique). Excessive IA monomer content leads to a considerable decrease in the $\mathrm{M}_{\mathrm{w}}$, increased PDI, and decreases in the thermal stability of PAN [51]. Preferably $\mathrm{M}_{\mathrm{w}}$ should exceed $200,000 \mathrm{~g} \cdot \mathrm{mol}^{-1}$, even though in this case PDI is possibly high and hinders polymer dissolution [4]. Living or controlled radical polymerization can be used to adjust PDI values in the range of 1.2 to 1.5 and achieve $\mathrm{M}_{\mathrm{W}}$ up to $300,000 \mathrm{~g} \cdot \mathrm{mol}^{-1}$, similar to the case of Reversible Addition-Fragmentation chain Transfer (RAFT) [26]. The advantage of RAFT is the possibility to 
synthesize copolymers with defined macromolecular architecture. A PAN copolymer with MMA was manufactured with up-scaled RAFT that had $\mathrm{M}_{\mathrm{n}}$ of $150,000 \mathrm{~g} \cdot \mathrm{mol}^{-1}$ and PDI of 1.7 ; the copolymer afforded fibers with high mechanical properties (due to improved spinning) that were transformed into CFs achieving tensile strength of $2.5 \mathrm{GPa}$. Performing similar RAFT at smaller (bench-lab) scale, PAN homopolymers with $\mathrm{M}_{\mathrm{n}}$ up to $130,000 \mathrm{~g} \cdot \mathrm{mol}^{-1}$ and smaller PDI values (around 1.3) were synthesized $[4,26]$.

Atom transfer radical polymerization (ATRP) has also been used for preparing PAN with low PDI. For example, when $\mathrm{Cu}_{2} \mathrm{O} / \mathrm{N}, \mathrm{N}, \mathrm{N}^{\prime}, \mathrm{N}^{\prime}$-tetramethylethylenediamine (TMEDA) was used as catalyst/ligand system, PAN with PDI of 1.2 was synthesized; addition of $\mathrm{AlCl}_{3}$ in the reaction mixture led to increase in the isotactic content [52]. Activation generated by electron transfer (AGET) ATRP has also been proposed for synthesizing PAN-block-PMMA copolymers that could be used as CF precursors with improved properties [53]. Additionally, substitution of metal catalysts or UV-radiation activated initiators with visible-light activated photocatalysts can benefit ATRP. For instance, using 4-fluoro-benzene-diazonium tetrafluoroborate, PAN copolymers were synthesized with $\mathrm{M}_{n}$ values between 1.2 and $2.7 \cdot 10^{5} \mathrm{~g} \cdot \mathrm{mol}^{-1}$ and PDI at approximately 1.3 [54].

In the last couple of years, template-assisted free radical polymerization with hexagonal crystalline metal salts such as $\mathrm{NiCl}_{2}, \mathrm{MgCl}_{2}$ has been proposed for synthesis of isotactic enriched PAN copolymers of IA or AA. The postulated reaction pathway resembles that of stereospecific heterogeneous catalytic polymerization; specifically, the hexagonally packed crystal salts adopt a layered structure and a thin layer of AN molecules are intercalated between them. Therefore, coordination interactions with metal ions impose a uniform orientation of the highly polar nitrile groups [55-57]. Thus, the rotation of the side group is restricted when the free radicals propagate, leading to higher probability of the isotactic addition. In one such work PAN copolymers were synthesized with maximum $M_{n}$ of $1.2 \cdot 10^{5} \mathrm{~g} \cdot \mathrm{mol}^{-1}$ and PDI of 2.5 [51]. ${ }^{13} \mathrm{C}$-enriched PAN by redox initiation in aqueous solution led to $\mathrm{M}_{\mathrm{n}}$ of about $4.5 \cdot 10^{5} \mathrm{~g} \cdot \mathrm{mol}^{-1}$ and PDI of 3 [41], achieving a relatively high value of molecular weight; this feature is appreciated in carbon fibers production, considering that higher molecular weight structures facilitate the production of thinner (in diameter) carbon fibers. Thus, mechanical properties should be elevated by reducing diameter, and consequently the defect density according to Griffiths law [58]. Similarly, PAN copolymer with IA using $\mathrm{MgCl}_{2}$ template technique reached a $\mathrm{M}_{\mathrm{n}}$ between 2.7-4.9.1 $0^{4} \mathrm{~g} \cdot \mathrm{mol}^{-1}$ and high PDI values (2.1-4.9) [57]. However, the most serious obstacle in regard to these techniques is the cost of scaling up.

High molecular weight PAN (HMWPAN) and Ultra High $\mathrm{M}_{\mathrm{W}}$ PAN (UHMWPAN) are difficult to process due to the high viscosity of the spinning dope and it is possible to manufacture fibers only by some kind of gel spinning process. Recently, UHMWPAN fibers were manufactured by a modified dry-jet gel spinning technique using a $\mathrm{P}(\mathrm{AN} @ \mathrm{MA})$ copolymer with $\mathrm{M}_{\mathrm{W}}$ higher than $1.7 \cdot 10^{6} \mathrm{~g} \cdot \mathrm{mol}^{-1}$ and PDI 1.7, reaching values of tensile strength over 1.0 GPa and modulus around 18.0 GPa [58]. These fibers have diameters between 4-6 $\mu \mathrm{m}$, which is smaller than the typically reported $7 \mu \mathrm{m}$ for the commercial PAN fibers. These fibers were used as feedstock for $\mathrm{CFs}$ that had improved mechanical properties; however, the improvement in CF performance lies squarely on the validity of Griffith law, i.e., the mechanical properties of fibers are inversely proportional to their filament diameter-(due to the lower concentration of defects in the cross section) [58]. Likewise, in [32] PAN fibers from polymers having $5.1 \times 10^{5} \mathrm{~g} \cdot \mathrm{mol}^{-1}$ were gel spun and used as CF precursor. The fibers had a bean-shaped fiber cross section and exceptional mechanical properties (e.g., reported Young modulus: $20.7 \mathrm{GPa}$ ); the CFs manufactured based on them had also higher Young modulus than commercial PAN-based CFs. This improvement was achieved by reducing the number of defects as well as their size: the average size of the defects in the initial gel-spun PAN fibers was estimated to be between $0.5 \mathrm{~nm}$ (attributed to chain ends) and $2.0 \mathrm{~nm}$ (due to chain entanglements), whereas in the final manufactured CFs the size of the defects was somewhat higher (at $2.4 \mathrm{~nm}$, originating from the heterogeneity between the size of the crystallites, as also observed via TEM).

The conformation of monomer sequences in PAN backbone is a parameter that could influence the structure of the CFs; the idea is that the stereochemical structure of the polymer could lead to 
further improvement of the turbostatic graphitic structure and thus improvement in carbonization yield. The stereochemical structure of PAN can be inferred from the ${ }^{13} \mathrm{C}$ NMR spectra and typically by three main peaks. PAN homopolymer exhibits three main peaks at $27-28 \mathrm{ppm}$ (assigned to the methine backbone groups, $-\mathrm{CH}<$ ), at 32-34 ppm (due to the methylene backbone units, $-\mathrm{CH}_{2}-$ ) and at $120 \mathrm{ppm}$ (attributed to the pendant nitrile groups, $-\mathrm{CN}$ ); more peaks might appear in the case of copolymers. The different strereochemical configurations are denoted by the combination of the fundamental structures that consist of two sequential structural units (which is termed dyad), which are designated racemo- $(r$ ) for the syndiotactic and meso- $(m)$ for the isotactic sequences, respectively. Due to the differences in their electronic environment, the different stereochemical structures might have a slightly different shift of then 13C signal; in such a case, the peaks tend to resolve into multiple peaks (with each peak representing molecular segments having different stereoregularity). The number of the peaks depends strongly on the specific measurement conditions (e.g., at high temperature the nitrile peak tends to resolve into pentaplet) $[15,59,60]$. Moreover, the area enclosed by each peak corresponds to the relative abundance of a specific structure and could be used for quantitative investigation of the respective probability distribution. In the case of PAN, the methine peak appears as a triplet peak under the most typical measurement conditions. The splitting of the peak is attributed to segments consisting of three structural units (i.e., triads) having different strereochemical conformations, with each peak assigned to the isotactic- (symbolized as $\mathrm{mm}$ ), the heterotactic- (symbolized as $\mathrm{rm}$ ) and the syndiotactic(symbolized as $r r$ ) triads. Table 1 showcases the distribution of the triads derived from the methine peak of PAN copolymers in comparison with results reported in the literature [41,52,60-62].

Table 1. Methine probability distribution of the triads for various polyacrylonitrile (PAN) polymers.

\begin{tabular}{|c|c|c|c|c|c|c|}
\hline \multirow[b]{2}{*}{ PAN Precursor } & \multicolumn{3}{|c|}{ Triad Probability Distribution } & \multicolumn{2}{|c|}{ Propagation * } & \multirow[b]{2}{*}{ Remarks } \\
\hline & $\underset{\text { (Isotactic) }}{\mathrm{mm}}$ & $\underset{\text { (Atactic) }}{\mathrm{mr}}$ & $\begin{array}{c}\text { rr } \\
\text { (Syndiotactic) }\end{array}$ & $\mathbf{P}_{\mathrm{m}}$ & $S^{* *}$ & \\
\hline P(AN@IA@MA) & 0.27 & 0.54 & 0.19 & 0.54 & $\mathrm{ND}^{* * *}$ & $\begin{array}{l}\text { Feed composition: } 93 \% \mathrm{AN}, 4 \% \mathrm{MA}, 3 \% \mathrm{IA} \\
\text { Solution-precipitation technique/Redox initiator } \\
\qquad \begin{array}{c}\left(\mathrm{K}_{2} \mathrm{~S}_{2} \mathrm{O}_{8} \text { and } \mathrm{Na}_{2} \mathrm{~S}_{2} \mathrm{O}_{5}\right) \\
\mathrm{M}_{\mathrm{W}}: 140,000 \mathrm{~g} \cdot \mathrm{mol}^{-1}\end{array}\end{array}$ \\
\hline Aq-PAN & 0.34 & 0.51 & 0.15 & 0.60 & ND & $\begin{array}{c}\text { PAN homopolymer } \\
\text { Solution-precipitation technique } / \mathrm{K}_{2} \mathrm{~S}_{2} \mathrm{O}_{8} \text { and } \\
\mathrm{Na}_{2} \mathrm{~S}_{2} \mathrm{O}_{5}\end{array}$ \\
\hline Com-PAN & 0.28 & 0.45 & 0.22 & 0.47 & 0.11 & commercial: textile-grade \\
\hline P(AN@IA) & 0.28 & 0.47 & 0.25 & 0.47 & 0.08 & $\begin{array}{l}\text { Feed composition } 98.5 \% \mathrm{AN}, 1.5 \% \mathrm{IA} \\
\text { Aqueous slurry technique/Free radical } \\
\text { initiator }(\mathrm{AIBN}) \\
\qquad \mathrm{M}_{\mathrm{W}}: 18,200 \mathrm{~g} \cdot \mathrm{mol}^{-1}[61]\end{array}$ \\
\hline${ }^{13} \mathrm{C}$ PAN & 0.34 & 0.38 & 0.28 & 0.44 & 0.17 & $\begin{array}{c}{ }^{13} \mathrm{C} \text { - enriched PAN homopolymer } \\
\text { Solution/precipitation technique } / \mathrm{K}_{2} \mathrm{~S}_{2} \mathrm{O}_{8} \\
\text { and } \mathrm{Na}_{2} \mathrm{~S}_{2} \mathrm{O}_{5} \\
\mathrm{M}_{\mathrm{W}}: \sim 450,000 \mathrm{~g} \cdot \mathrm{mol}^{-1}\end{array}$ \\
\hline Tol-PAN & 0.26 & 0.50 & 0.23 & 0.51 & 0.01 & $\begin{array}{l}\text { PAN homopolymer } \\
\text { Solution technique/AIBN [60] }\end{array}$ \\
\hline ATRP-PAN & 0.23 & 0.46 & 0.31 & 0.43 & 0.06 & $\begin{array}{l}\text { PAN homopolymer } \\
\text { ATR polymerization: } \mathrm{AlCl}_{3} / \mathrm{AN} \text { molar ratio: } 0.01 \text { [52] }\end{array}$ \\
\hline Iso-PAN & 0.37 & 0.48 & 0.15 & 0.54 & 0.12 & $\begin{array}{c}\text { PAN homopolymer } \\
\text { Stereospecific polymerization (urea-canal complex, } \\
-78^{\circ} \mathrm{C} \text {, isotactic-rich) }[28,60]\end{array}$ \\
\hline At-PAN & 0.25 & 0.51 & 0.24 & 0.51 & 0.01 & Suspension polymerization \\
\hline Iso-PAN-1 & 0.48 & 0.36 & 0.16 & 0.69 & 0.08 & Polymerization with organometallic compounds \\
\hline Iso-PAN-2 & 0.58 & 0.29 & 0.13 & 0.74 & 0.10 & Polymerization with organometallic compounds \\
\hline Iso-PAN-3 & 0.68 & 0.22 & 0.10 & 0.79 & 0.10 & $\gamma$-irradiation (urea-canal complex) [63] \\
\hline PAC/01 & 0.48 & 0.37 & 0.15 & 0.52 & 0.24 & $\begin{array}{c}\text { Feed composition: } 98.5 \% \mathrm{AN}, 1.5 \% \text { IA } \\
\text { Template assisted }\left(\mathrm{NiCl}_{2}, \mathrm{MgCl}_{2}\right) \text { solid phase } \\
\text { polymerization/AIBN } \\
\text { Mw: } 25,700 \mathrm{~g} \cdot \mathrm{mol}^{-1}[61]\end{array}$ \\
\hline
\end{tabular}


Table 1. Cont.

\begin{tabular}{|c|c|c|c|c|c|c|}
\hline \multirow[b]{2}{*}{ PAN Precursor } & \multicolumn{3}{|c|}{ Triad Probability Distribution } & \multicolumn{2}{|c|}{ Propagation ${ }^{*}$} & \multirow[b]{2}{*}{ Remarks } \\
\hline & $\underset{\text { (Isotactic) }}{\mathrm{mm}}$ & $\underset{\text { (Atactic) }}{\mathrm{mr}}$ & $\begin{array}{c}\text { rr } \\
\text { (Syndiotactic) }\end{array}$ & $\mathbf{P}_{\mathrm{m}}$ & $\mathrm{S}^{* *}$ & \\
\hline
\end{tabular}

${ }^{*}$ The values for the probability of $\mathrm{m}$-propagation $\left(\mathrm{P}_{\mathrm{m}}\right)$ assuming Bernoullian statistics were calculated as the average from the respective values, [64] and (when possible) [65]. ${ }^{* *} \mathrm{~S}$ : Standard Deviation between the values used for calculating $\mathrm{P}_{\mathrm{m}} .{ }^{* * *} \mathrm{ND}$ : Could not be defined because " $>0.50$ " [65].

From the reported values in Table 1 , it is clear that PAN tacticity is affected by the polymerization method (i.e., solvent, initiator, presence of catalyst) as well as the use of commonomers. For example, the values of PAN originating from solution/precipitation techniques show that these polymers are isotactic rich, indicating a preference of the meso- addition; some recently synthesized 13C-enriched PAN homopolymers using the same technique also showed a preference to isotactic sequences [41]. AN forms strong polar bonds with water and this probably leads to some kind of steric hindrance effect. Moreover, it seems that the selection of the initiator system (which also influences the selection of the polymerization temperature) might have some effect on the resulting tacticity; in Table 1, the polymers $\mathrm{P}(\mathrm{AN} @ \mathrm{IA} @ \mathrm{MA})$ and Aq-PAN that were synthesized using redox initiator (at room temperature) have somewhat higher amount of isotactic sequences than the P(AN@IA), which was similarly synthesized but using free radical initiator (at $50{ }^{\circ} \mathrm{C}$ ). A small preference towards isotactic segments was also observed in the case of atactic PAN (synthesized with solution polymerization in toluene) by Minagawa et al.: its finely resolved 13C NMR spectrum leans slightly towards isotactic sequences instead of syndiotactic ( 0.26 vs. 0.23) [60]. Hao et al. involved ${ }^{13} \mathrm{C}$ NMR studies to prove the trend of radically polymerized PAN to form atactic, helically packed structures $[23,55]$.

Hou et al. [66] performed suspension polymerization of $\mathrm{AN}$ in $\mathrm{H}_{2} \mathrm{O} / \mathrm{DMF}$ mixtures with variable content of ammonium itaconate (AIA). A linear connection of isotacticity with the logarithm of $\mathrm{M}_{\mathrm{w}}$ and the comonomer content was claimed. Increase in $\mathrm{M}_{\mathrm{W}}$ is assisted by $\mathrm{H}_{2} \mathrm{O}$ addition and is derived by radical transfer reactions in presence of DMF. Reactivity ratios for aqueous systems are $\mathrm{r}_{1 \text { (AN) }}=0.76$ and $\mathrm{r}_{2 \text { (AIA) }}=1.39$ [12,67]. Any decrease in isotacticity can be attributed to distortion of AN sequences by AIA units. As in the case of Iso-PAN (Table 1) [28], AN/urea ratio, temperature, and aging time promote large isotactic triad contents $(50 \%-90 \%)$, and even $99 \%$ has been reported by a modified process [55]. Recently, template assisted bulk free radical polymerization in the presence of hexagonal metal salts like $\mathrm{MgCl}_{2}$ and $\mathrm{NiCl}_{2}$, and anionic polymerization delivered up to $70 \%$ isotactic-enriched PAN copolymers [55,61,62,68].

It should be noted that the analysis of the statistics is more accurate when peaks with multiplicities higher than three are available. Splitting of peaks can be achieved by performing the NMR measurement at higher temperatures, as exemplified in the work of Katsuraya et al. [60]. The multiplets can be further quantitatively exploited through the determination of the probability for the addition of new structural units. In the simplest case, only one probability value is necessary, i.e., that of the $m$-propagation, $\mathrm{P}_{\mathrm{m}}$, (or, equivalently, that of the $r$ - propagation, $\mathrm{P}_{\mathrm{r}}$, whereby definition: $\mathrm{P}_{\mathrm{m}}+\mathrm{P}_{\mathrm{r}}=1$ ). In such a case, the sequence distribution is described by the Bernoullian statistics. In such cases, the relative amounts of the triads will be: $[\mathrm{mm}]=\mathrm{P}_{\mathrm{m}}{ }^{2},[\mathrm{rm}]=2 \mathrm{P}_{\mathrm{m}}\left(1-\mathrm{P}_{\mathrm{m}}\right),[\mathrm{rr}]=\left(1-\mathrm{P}_{\mathrm{m}}\right)^{2}$. Thus, the probability distribution of the triads in methine peak can be used to calculate the value of $\mathrm{P}_{\mathrm{m}}$. However, it is possible that the stereochemistry of the addition reaction could be more complex. This happens when the configuration at the end of the chain influences the probability of the monomer addition. For example, when the stereoregularity of the last monomer unit affects the addition of the new monomeric unit, then two probability parameters are needed to describe the stereochemical sequencing; these are termed $\mathrm{P}_{\mathrm{r} / \mathrm{m}}$ 
(i.e., the probability of $m$ - addition in an existing $r$ - ended chain) and $\mathrm{P}_{\mathrm{m} / \mathrm{r}}$ (i.e., the probability of $r$ addition in an existing $m$ - ended chain). Such cases are described by the $\mathrm{n}$-th order Markov statistics (where $\mathrm{n}$ the number of structural units of the chain end that affect the propagation) [59]. For example, in case of P(AN@IA@MA) copolymer in Table 1, Bernoullian statistics are not accurate, and possibly a 1st (or even a 2nd) order of Markov statistics might be necessary. Generally, the stereochemistry of PAN chain growth has not been extensively investigated. The 2-D solid state NMR analysis of redox-polymerized- ${ }^{13} \mathrm{C}$-enriched- atactic PAN, found that the distribution of the torsion angles has a rate of trans to gauche of about 9:1 showing again the preference of PAN towards isotactic structures [69] and that the torsion angles in trans-trans, such as meso- dyads deviate by $10-20^{\circ}$ from the ideal trans conformation. As a result, an angle of around $20^{\circ}$ between adjacent $\mathrm{CN}$ groups is the most probable structure [70]. NMR studies are critical in PAN-based CFs manufacturing, especially when the macromolecular network affects the transition from the liquid to the solid phase during spinning.

The motivation of this work is to review the advances of CF processing with attention to chemical structure evolution. Even though the effect of comonomers on stabilization has been investigated extensively, aspects in stereochemistry of PAN remain unclear. Thus, in the second and third part of this work, recent advances tackle this subject. The change of the thermomechanical properties during transition to ladder polymer is also discussed. The scenery could be altered by recent studies on CFs synthesis with properties that hold a lot of promise to enable application in the demanding automotive field. Several modifications of the basic process are reported; processing impact is presented in relation to CFs performance, in order to visualize the next steps in CF manufacturing in the whole spectrum of structural engineering to satisfy modern needs. Finally, in the Appendix A, supportive information regarding the physical structure of PAN fibers derived by the spinning process are provided for completeness.

\section{Structural Transformations during Stabilization}

\subsection{Stereochemical Configuration of PAN and Its Effect on the Structure}

The effect of stereochemical structure on reactions chemistry is somewhat puzzling. Initially, it was suggested by Coleman that isotactic sequences react via intramolecular nitrile cyclization, whereas syndiotactic units react towards intermolecular cross-linking; intramolecular cyclization initiates sequentially in the adjacent chain [71]. Further inroads on this topic were achieved with the investigation of stabilized PAN stereochemical structure, and the only way to investigate is through solid state (ss) ${ }^{13} \mathrm{C}$ NMR, as it is insoluble. This is a rather uncommon method and until recently the measured spectra were of poor quality [72]. A significant step forward was achieved with the introduction of improved measurement techniques, such as the direct polarization/magic angle spinning (DP/MAS), as well as the various 2D correlation experiments such as ${ }^{13} \mathrm{C}-{ }^{13} \mathrm{C}$ 2D INADEQUATE. Moreover, devices operating at higher resonance frequencies were made available, and PAN labelled with ${ }^{13} \mathrm{C}$ at specific positions was utilized, leading to the acquisition of high resolution $\mathrm{ss}{ }^{13} \mathrm{C}$ NMR spectra. In one publication, ${ }^{13} \mathrm{C}$ enriched PAN was heat treated at inert atmosphere; through $2 \mathrm{D}$ measurements the possible correlations between different chemical structures were investigated and the authors proposed a possible pathway for the reaction, with the main conclusion reached that heat treatment of PAN at inert atmosphere leads to a structure consisting mainly of isolated pyridine units [73]. Further investigations verified that the material formed during thermal treatment of PAN at inert atmosphere contains isolated rings and end groups, indicating that the polymer undergoes severe decomposition reactions. [41,73,74], Presumably, this is the result of the intense heat flow due to the abrupt exotherm evolved from the nitrile cyclization that leads to uncontrollable chain scission $[74,75]$.

Based on the structures determined through ss NMR, the reaction pathway of oxidative stabilization was proposed, showing that oxidative dehydrogenation is the first step for cyclization, as well as for verifying extent of oxidation and crosslinking reactions. It was proposed that chain conformation was not important and temperature-induced chain flexibility could be sufficient to provide inter- and 
intra-molecular reactions [74]. Contrarily, the investigation of isotactic-rich P(AN@IA) cyclization, showed that the reaction progressed faster in isotactic PAN sequences, even though the extent of conjugation was not affected by either tacticity or IA presence $[57,68]$. However, the results from the work of Hou et al. with the different sets of AN/AIA copolymers indicate that there is a correlation between the stereochemical structure of PAN and kinetics of cyclization and comonomer content affected reaction progress [66]. Moreover, an interesting hitherto unmentioned fact is the possibility that dehydrogenation reactions could produce polyenes having cis- and trans-isomeric structures, but it is not clear how this could affect structure [76].

\subsection{Thermomechanical Transformation of PAN}

Change of fiber length can be directly associated with the thermomechanical behavior as one of the most characteristic and macroscopically evidenced changes during stabilization. Temperature, time and applied stress affect the length change in a complex manner [72,77-79]. This phenomenon is attributed to the synergy of physical shrinkage (due to the entropic recovery during stabilization), creep and cyclization induced shrinkage, which is linked with the nitrile cyclization reactions [80,81]. Length change is an attractive candidate for online monitoring and control of stabilization process, but yet little progress is evidenced to quantitatively correlate length change with PAN properties. The main reason is its rather complex behavior due to plethora of phenomena that occur during stabilization and it is challenging to use more than semi-quantitative descriptors [80].

Low temperature processing induces length change due to the thermoplastic character of PAN before structure transformation [72]. At higher treatment temperature the shrinkage can be directly correlated with the kinetics of cyclization, and its stereochemistry [82], an idea that was further developed in the literature [83-85]. Intra-molecular cyclization induces macromolecular rotation, which indicates that the maximum chemical shrinkage is actually dependent on the ratio of inter- to intra- molecular nitrile reactions, (as postulated by Fitzer et al.) [80,82]. Concerning the change of length, secondary creep of the polymer could lead to elongation, dependent on treatment variables [86]. It is difficult to determine the complex outcome of stabilization on the physical structure of PAN and this can be seen in the work of Sabet et al. where twelve different possible combinations of structural rearrangements were identified $[79,87]$. In this direction, a methodology was proposed for separating the contributions of entropic recovery, creep and chemical shrinkage [86]. Deconvolution permitted a more clear association between the length change under different treatment conditions and the structural transformations that PAN fibers undergo $[79,86]$. Isothermal treatment beneath the onset of cyclization could lead to elongation of fibers, while additional increases in density, crystallinity, and crystallite size are observed [88]. These phenomena can be correlated to the structural changes particularly in the ordered regions. Stretching prior to cyclization influenced further growth and densification of the ordered regions [64]. Heat treatment leads to the onset of cyclization reactions, but sequences of unreacted fragments still exist at even higher temperatures, while change in length may reach a plateau maximum value [82].

One of the most important tools for investigating the thermomechanical behavior of PAN is Dynamic Mechanical Analysis (DMA), which detects polymer transitions $[63,89,90]$. Fibers are subjected to a proper oscillation mode (may consist of more than one frequency) with simultaneous temperature ramping. The results of DMA are represented using complex modulus $E=E^{\prime}+I \times E^{\prime \prime}$, where $E^{\prime}$ is the real part and is usually termed storage modulus. The imaginary part of the modulus $E^{\prime \prime}$ is termed loss modulus. Another quantity used for analyzing the thermomechanical behavior is the ratio E"/E', known as loss factor $(\tan \delta)$.

Figure 1 is an indicative chart of the loss factor $\tan \delta$ versus temperature for commercial PAN fibers [90]. Two peaks are observed: the first is centered at $90^{\circ} \mathrm{C}$ and is quite broad, spanning between 50 and $120^{\circ} \mathrm{C}$, with two shoulders around 70 and $150{ }^{\circ} \mathrm{C}$. The second is detected at $270{ }^{\circ} \mathrm{C}$; the position of the latter peak is independent of frequency, indicating that it should be attributed to cyclization reactions, which are dominant during stabilization. The former peak corresponds to the main transition 
of PAN; this is different than typical glass transition of an amorphous polymer [91]. Following the interpretation of Bashir [89], this corresponds to the transition of the ordered phase from mesophase glass to mesophase melt. As already mentioned, these regions are described as hexagonal mesophase, with ordering in two dimensions [90,92]. Moreover, the shoulder at $150{ }^{\circ} \mathrm{C}$ can be correlated to the transition on the amorphous phase from the glassy to the rubbery state [89]. The low intensity indicates a rather low degree of orientation, since in oriented PAN the single transition is observed of the ordered phase [89]. The PAN fibers investigated resemble that of the copolymers used in by $\mathrm{Yu}, \mathrm{He}$, and Bai et al. [49,93,94], which exhibit hexagonal packing structure-similarly to homopolymer PAN [89]. Undrawn films of PAN copolymers with high amount of comonomer between 13 and $30 \mathrm{~mol} \%$ exhibit a single transition in the region of $75^{\circ} \mathrm{C}$, opposite to two transitions of homopolymer PAN at 78 and at $121^{\circ} \mathrm{C}[91,95]$.

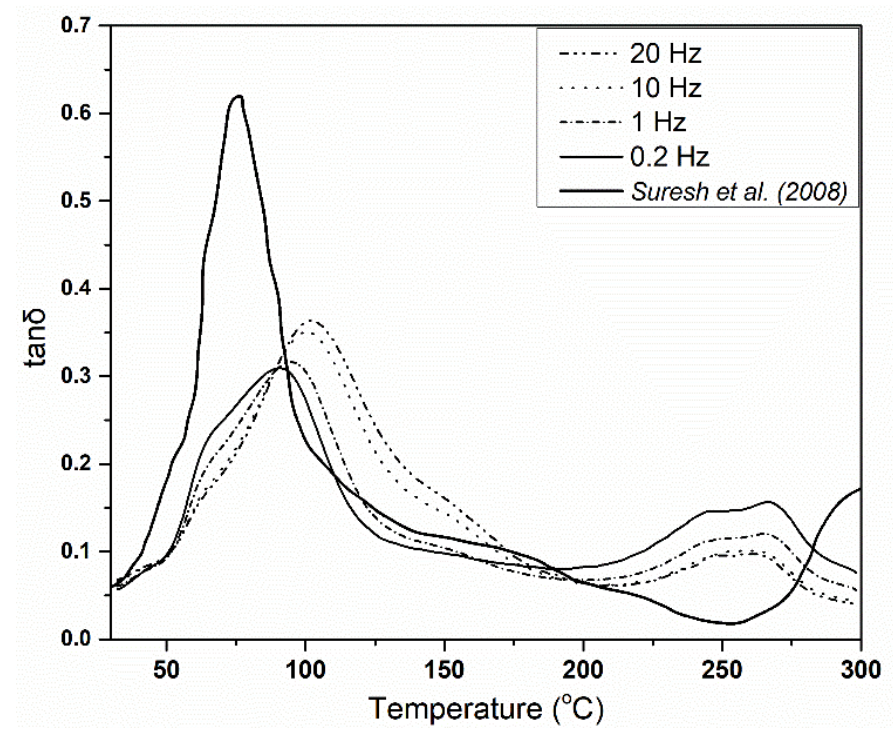

Figure 1. Loss factor $(\tan \delta)$ versus temperature of commercial PAN fibers enriched with literature data [90].

Bashir measured the DMA of undrawn and unoriented films of homopolymer PAN at the frequency of $1 \mathrm{~Hz}$, where two peaks were found (at 90 and $140{ }^{\circ} \mathrm{C}$ ), which after drawing merged into a single broad peak at about $85^{\circ} \mathrm{C}$ [89], whereas compression molded PAN sheet also exhibited two peaks at 93 and $130^{\circ} \mathrm{C}$. Sawai et al. [63] interpreted the behavior of PAN fibers as the result of three relaxation phenomena; $\alpha$ transition (at $150{ }^{\circ} \mathrm{C}$ ), $\beta_{\mathrm{c}}$ transition (at $100^{\circ} \mathrm{C}$ ) and $\gamma$ transition (at $25^{\circ} \mathrm{C}$ ). $\alpha$ transition was assigned to helical sequences of molecular motions in the amorphous phase-like Bashir [89]-, whereas both $\beta_{\mathrm{c}}$ - and $\gamma$ - transition were assigned to segmental motions of planar zig-zag sequences in paracrystalline phase [63]. It was found that the DMA depended on the degree of drawing, and to a lesser extent, on the isotactic content of PAN. The first transition appeared only in the undrawn gel film irrespective of the polymer tacticity. The second was not detected in case of the ultra-drawn atactic PAN film and the latter appeared only for drawn atactic PAN [63]. There are indications that this transition depends on the presence of co-crystallized solvent like DMF, which can be eliminated when the solvent is removed [96]. Sawai et al. [63] performed multi-frequency DMA measurements and found that each transition exhibited an Arrhenius type relation. The proposed correlation between frequency and temperature indicates that relaxation is a rate-determined process [63]. A similar result was derived from modelling of length change during isothermal treatment [86].

\subsection{Outcome of Thermal Treatment: Pre-Oxidized vs. Stabilized PAN Fibers}

Temperature arises as the critical factor to achieve complete transformation to thermoset ladder polymers. There are numerous studies that investigate carbonization and correlate the mechanical properties of CFs with the extent of cyclization, oxidation, and overall stabilization. It has been 
reported that high strength CFs can be derived when stabilization progress is within $41 \%-60 \%$. These investigations demonstrate that there is no need for complete change in thermomechanical performance and time-consuming thermal treatment to achieve a proper stereochemical configuration. However, below $40 \%$ of oxidation void formation is reported, and thus mechanical properties upon carbonization are decreased [19,31]. Following these claims, PAN fibers should be evaluated for their potential to resist carbonization treatment and simultaneously for their ability to comply with the high standards regarding mechanical performance. Several target values have been proposed for evaluating the effectiveness of stabilization for optimum CF synthesis based on the physical properties or chemical composition $[1,35]$. For example, the oxygen content has been proposed as a critical index, even though the optimal amount reported from various researchers is under controversy; typically, values vary at $8 \%-12 \%[1,3,11,35-38]$, and 12\%-21\% [10]. Apparently, this discrepancy could be attributed to PAN composition. Another highly appreciated parameter is fiber density, with desirable values for stabilized fibers varying between 1.34 and $1.39 \mathrm{~g} / \mathrm{cm}^{3}$ [1,33], or $1.40 \mathrm{~g} / \mathrm{cm}^{3}$ [38]. Krishnan et al. proposed a linear relationship of density and oxygen content in the range of $1.40-1.49 \mathrm{~g} / \mathrm{cm}^{3}[40,68]$, while Nunna et al. also revealed linearity in the dependence of temperature on degree of oxidation [34]. Other methods have been also proposed for evaluating stabilization treatment, like the absorbance of humidity, the hydrogen content [2] or the change of the shrinkage stress [97]. Nunna et al. introduced a methodology involving Raman spectroscopy and wide angle $X$-ray diffraction signal processing to determine oxygen distribution in the skin and core region of stabilized PAN fibers, to monitor the chemical processes and the structure assembling, as well as the formation of the graphitic planes [34]. Again in this case, it was concluded that the increase in tensile strength was connected with the decrease in CF crystallite size, and/or flaws and defects with lower size than $0.6 \mu \mathrm{m}[8,68]$, which are determined by intermolecular cyclization and oxidation propagation [10]. Contrarily, it was reported that increase in crystallite size had no effect and any reduction was due to loss of preferred orientation [98].

However, apart from density, which could be correlated with oxygen content $[40,68]$, and FTIR spectroscopy [99-103], other analytical techniques can hardly be involved for the in situ monitoring of stabilization. The most widely applied methods are X-ray diffraction [104-106] and DSC [101-103,107-110]. This analysis is based on the ratio of measured exotherm of the precursor and the oxidatively heat treated PAN. What is more, each of these methods has its own limitations and could not serve for online quality control. More specifically, there is a tendency in DSC to overestimate the extent of stabilization, especially in high yields of the related reactions and XRD leads to underestimation [108].

The FTIR seems a more reliable method, regarding the possibility to monitor nitrile to methylene ratio and conjugation index that are indicative for the type and the extend of the reactions. Extensive studies are available for the analysis of FTIR spectral evolution during PAN heat processing $[51,57,95,111,112]$. The peaks that are more important for this task are that of the nitrile groups at $2240 \mathrm{~cm}^{-1}$, of the methylene backbone units at $2940 \mathrm{~cm}^{-1}$, and of the conjugated double carbon and carbon-nitrogen bonds at $1600 \mathrm{~cm}^{-1}[72,82,99,102]$. The peak at $1382 \mathrm{~cm}^{-1}$ due to C-H bending and $\mathrm{CH}_{2}$ wagging of $\mathrm{C}=\mathrm{C}$ present in $\mathrm{CFs}$ is qualitatively consumed, which indicates that $2940 \mathrm{~cm}^{-1}$ methylene peak may be amplified by humidity. Both peaks of 1200 to $1100 \mathrm{~cm}^{-1}$, originated by the wagging vibration and in plane bending ( $\mathrm{p}$-substituted benzenes) of $\mathrm{C}-\mathrm{H}, \mathrm{C}-\mathrm{C}$, and $\mathrm{C}-\mathrm{OH}$ bonds are progressively reduced with every additional thermal step. This fact may be attributed to an increase in carbon yield for processes at higher stabilization temperatures and $\mathrm{sp}^{2}$ graphitic planes formation evidence can be provided by the respective increase in the peak at $1600 \mathrm{~cm}^{-1}$ (Figure 2) $[31,103,113-117]$. The initiation of stabilization reactions might induce a prominent peak at $1710 \mathrm{~cm}^{-1}$ due to the carbonyl units, which are not present in the initial spectrum. The peak at $1730 \mathrm{~cm}^{-1}$ is attributed to the carbonyl present in the comonomer composition of PAN [13,31]. It is revealed that during the initial steps of stabilization, oxidation reactions might also become important. Moreover, by the end of carbonization, complete removal of the carbonyl groups is expected (Figure 2) [28,72,82].

Current industrial needs push research towards procedures that could be favorable for adaptation into continuous processes and introducing modern analytical technologies applicable to large scale 
manufacturing lines. A very recent work by Zhang et al. demonstrated the advantages of microwave heating over conventional processing. It was reported that dehydrogenation duration could be cut up to $50 \%$, while fiber structure was less defective due to more uniform heating from the core to skin [31]. Moreover, microwave technology is using lower energy compared to conventional processing, whereas real time temperature control and automation ability favor industrial application [31]. Thus, modern characterization is demanded to support quality control efficiently. Real time 2D correlation FTIR Spectroscopy was developed and applied investigating the oxidative treatment of commercial PAN fibers and the in-depth analysis of the reaction pathway [111]. Such developments open a new way for massive data collection on PAN oxidative stabilization and is expected to improve our understanding of reaction mechanisms.

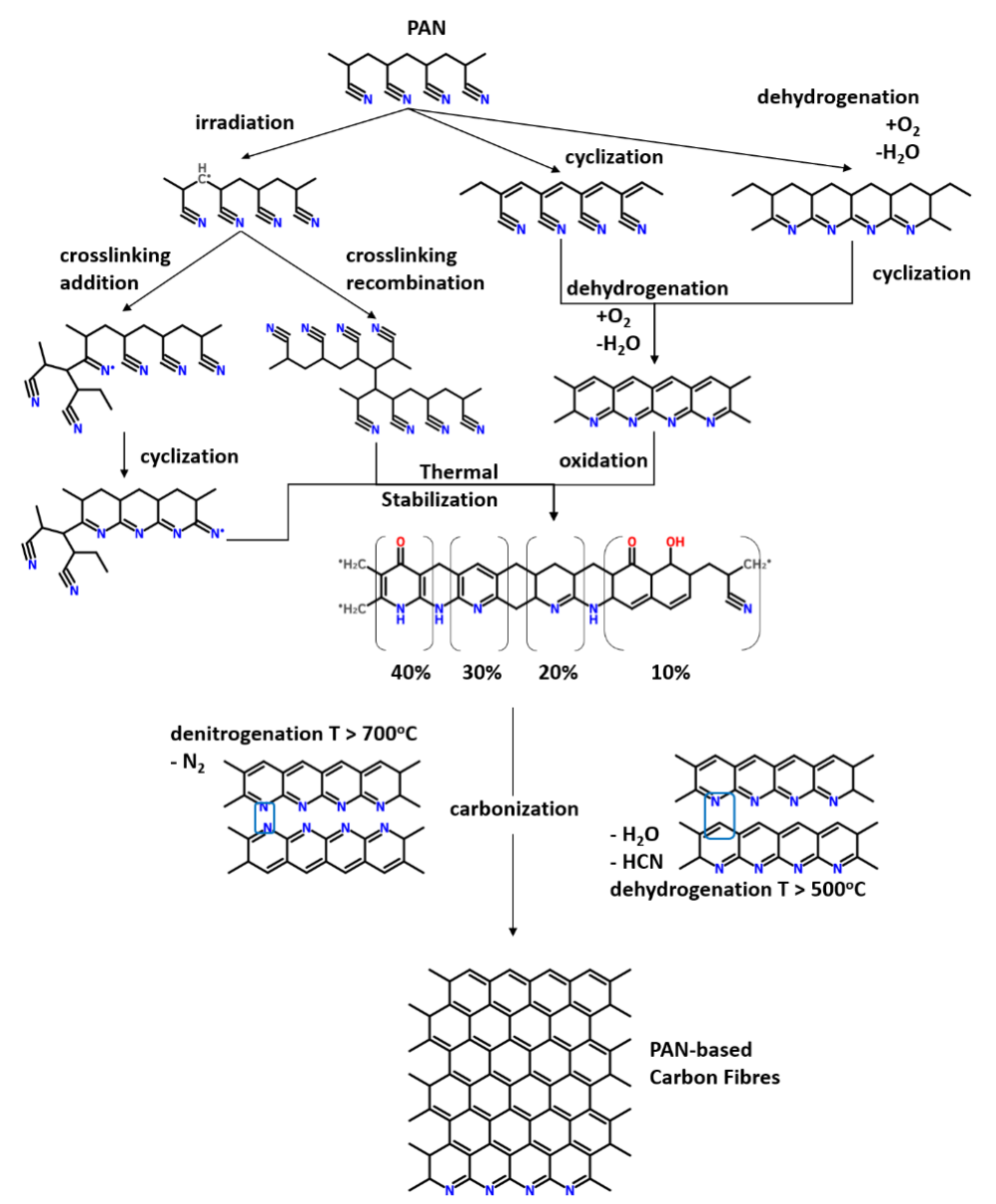

Figure 2. Chemical evolution of PAN fibers into carbon fibers.

\section{Alternative Pre-Treatments towards High Performance of Carbon Fibers}

Production of CFs falls into the types of standard grade with modulus range 230-240 GPa, high strength and intermediate modulus (HSCFs) 280-300 GPa (also reported as type II), high strength and high modulus (HMCFs) 350-480 GPa (type I), and ultra-high modulus (UHMCFs) 500-600 GPa [11,98]. Nonetheless, UHMCFs service demands are usually met by mesophase pitch based graphitic fibers (GFs), which yield to enhanced orientation of the graphene sheets [2,3]. In summary, several methods were applied in recent years in order to enhance CF mechanical properties. These approaches focus on several aspects regarding synthesis of PAN precursor, spinning, and thermal processing. An extensive review of the relevant literature led to composing Figure 3. It is very interesting to mention that tensile strength of commercially available CFs has improved only by $1.2 \mathrm{GPa}$ in the past 23 years, while most significant proceedings seem to have been achieved with Young modulus optimization with an increase of almost $90 \%$. Still, the possibility to meet or even 
overcome the performance of commercially available CFs by adopting more energy-efficient irradiation technologies, with emphasis to microwave-plasma, raises the interest for further developments and commercialization of even stronger CFs in the near future. Additionally, it was revealed that low density hollow $\mathrm{CFs}$ have the potential to meet the specifications for the automotive industry, which is encouraging to widen the CF composite market and applications by the increased performance to weight ratio [118]. The scope of the following subsections is to visualize all these aspects and shed light on up-to-date proceedings and to contribute to evolving research.

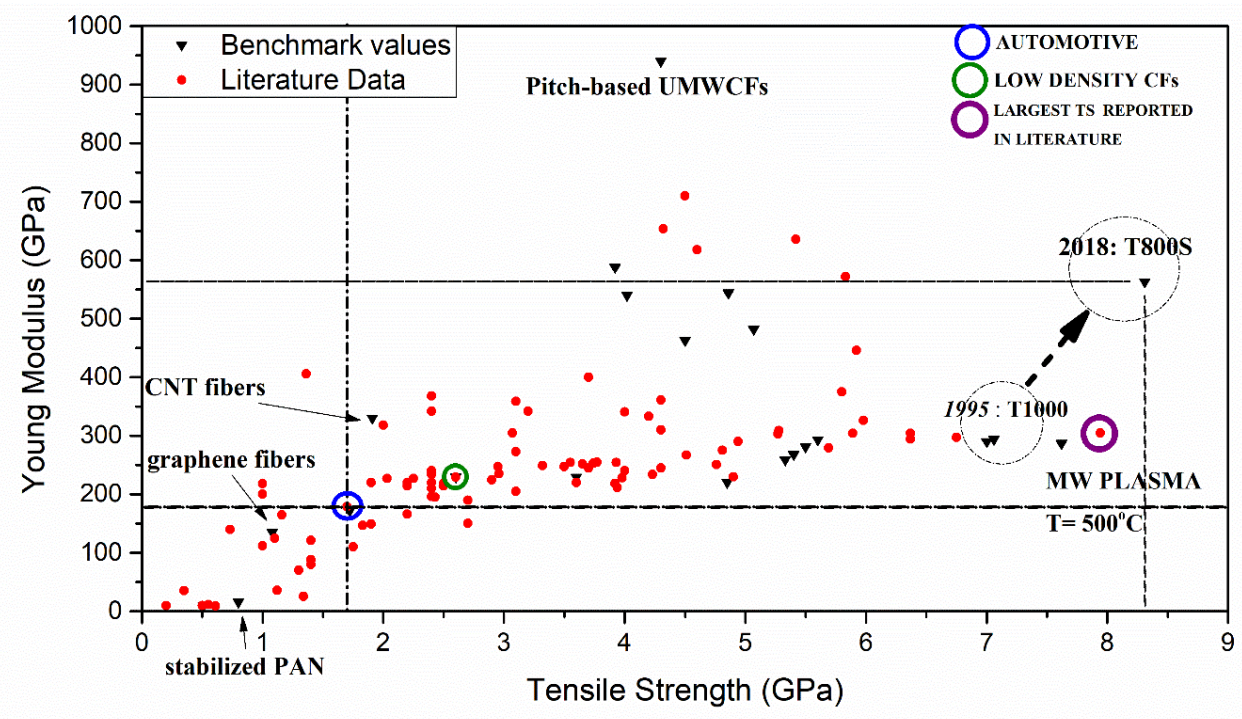

Figure 3. Young Modulus vs. Tensile Strength: Benchmark values and literature data are reported $[1,2,5,8,10-13,16,19,20,24,29,32,39-41,64,75,98,116,118-129]$.

\subsection{Carbon Fiber Performance Relation on Chemical Features}

In the scope of precursor synthesis, improvement of PAN copolymer was applied in molecular design including composition, sequence and molecular tacticity. Monomer composition does not play an important role, but the total content in functionalities does by lowering the activation energy of stabilization reactions and leading to enhanced crosslinking and improved carbon yield [27]. Though, a holistic aspect is still hard to obtain. Figure 4 is an effort to meet this need and reveal a trend of the literature data.

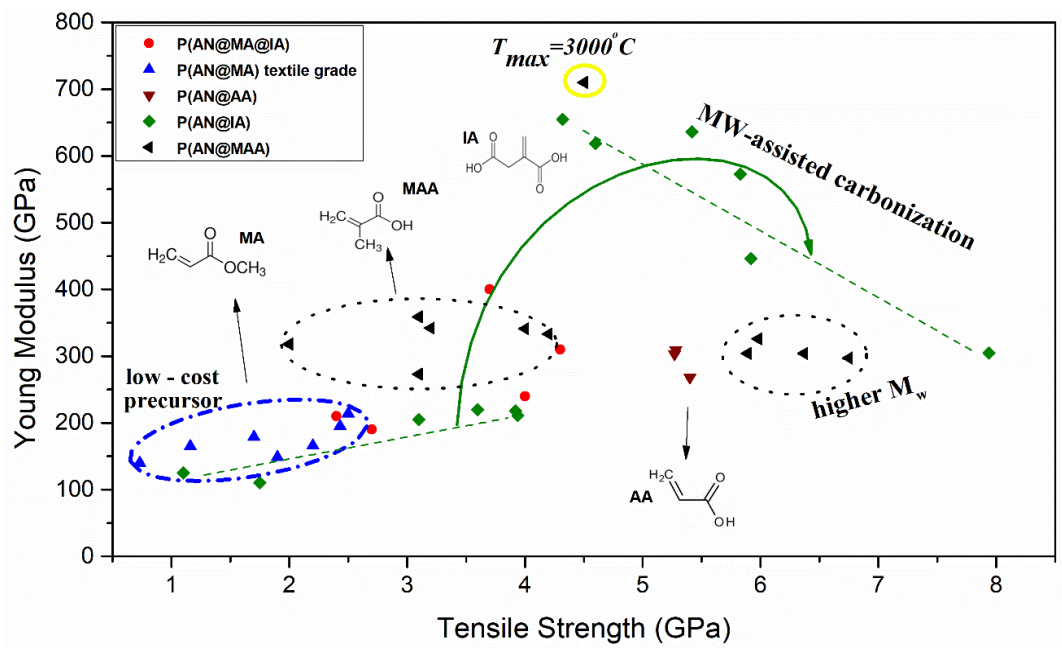

Figure 4. Carbon fiber (CF) performance dependence on chemical composition based on literature data presented in Figure 3. 
Firstly, low-cost textile grade and melt-spun PAN commonly composed by over $10 \mathrm{~mol} \%$ of various monomers such as MA, demonstrate lower performance. However, it is not discouraging, as the values achieved are not far from threshold properties to meet automotive specifications of $1.72 \mathrm{GPa}$ and $172 \mathrm{GPa}$ in the case of tensile strength and modulus. $\mathrm{M}_{\mathrm{W}}$ might be more important than chemical composition to achieve high-end performance of CFs. Morris et al. used an ultra-high $\mathrm{M}_{\mathrm{W}}$ precursor of $1,700,000 \mathrm{~g} \cdot \mathrm{mol}^{-1}$ and tensile strength at $4.3 \mathrm{GPa}$ and modulus at $361 \mathrm{GPa}$ were increased compared to other MAA copolymers. This is attributed to Griffith law; the viscous spinning dope derived a lower diameter than typical for PAN fibers and led normally to enhancement in tensile properties [32]. Regarding this precursor, huge advancement of tensile properties was achieved upon low temperature microwave plasma assisted carbonization, a technology that is expected to attract further attention in the following years. It would be of great interest if the same trend is followed for other copolymer precursors, which could lead to more eco-friendly and low-cost HSCFs and UHMCFs.

\subsection{Stabilization Advances to Engineer Optimized Carbon Fiber Performance}

Stabilization is extensively studied; yet adaptation of trial-and-error experimentation still is dominant to settle an industrial scale process. Research on irradiation technologies that accelerate the rate determining step of oxygen diffusion, and may improve radial heterogeneity of PAN evolution to CFs, may be a bright field for research to influence severe reactions. Advances could be achieved since a solid engineering methodology is proposed to increase oxygen diffusion and secure uniform reactivity in the fiber axis other than time-extended stabilization [33,72]. Both Figures 5 and 6 show enhanced heat dissipation upon stabilization with irradiation technologies to reach properties in the class of HMCFs and UHMCFs.

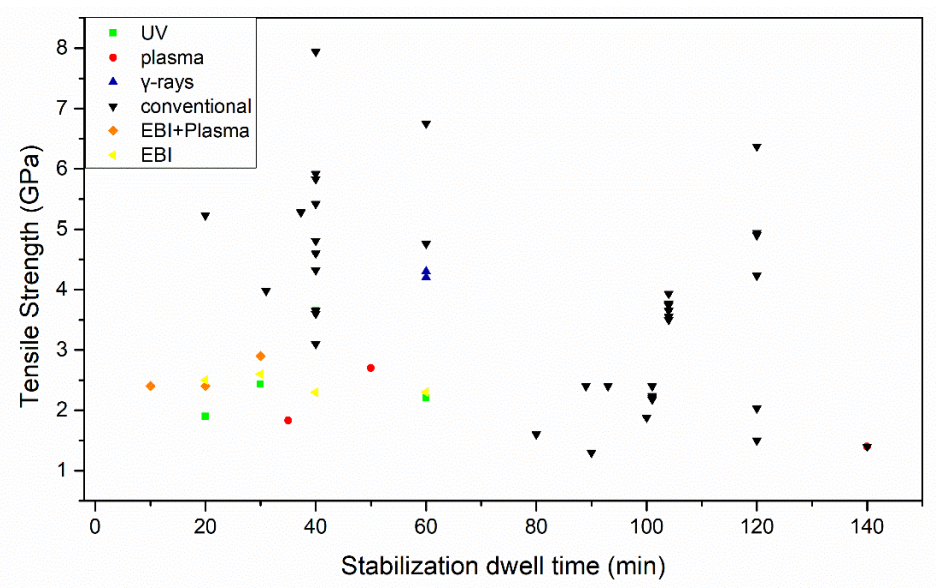

Figure 5. Tensile strength versus stabilization duration based on literature data presented in Figure 3.

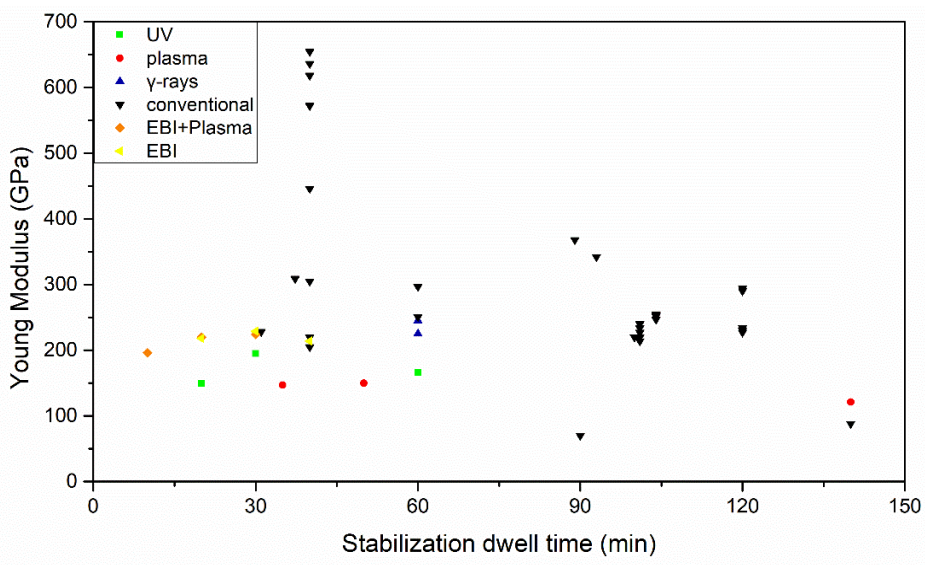

Figure 6. Young modulus versus stabilization duration based on literature data presented in Figure 3. 
An interest has been revived in low-temperature heat treatment (pre-stabilization), as a method for improving stabilization uniformity [82]. Even if restricted disorientation of PAN molecules and increment in preferred crystallite orientation lead to low increment of $16 \%$ in the tensile strength [121], time-extension of heat treatment hinders productivity. Moreover, Szatkowski et al. reported stabilization at $250{ }^{\circ} \mathrm{C}$ and $280{ }^{\circ} \mathrm{C}$ for a total duration of $7 \mathrm{~h}$, or $14 \mathrm{~h}$ when adopting a temperature program in the range between 150 and $230^{\circ} \mathrm{C}$ [14]. The manufactured $\mathrm{CFs}$ had a higher density than $1.75 \mathrm{~g} / \mathrm{cm}^{3}$, smaller interlayer spacing, lower porosity, and better preferred orientation, which led to a considerable increase in tensile strength and Young's modulus [75,98]. Additionally to this approach, further investigation was performed in regards to mild oxidative processing to feed carbonization with stabilized PAN fibers of optimum physical composition, since the stabilized structure is inherited to CFs [10]. This was engineered with proper tension control during stabilization to prevent loss of the polymer ordered structure, and prevent the hindering effect of high applied stress on thermochemical transformations [64]. Microwave plasma stabilization has been proposed for effective treatment of large-tow PAN bundles (up to $24 \mathrm{~K}$ monofilaments), combining atmospheric pressure plasma with conventional heating. This led to decrease in conventional processing duration from several hours to just $30 \mathrm{~min}$. Similar cost reduction was reported by Huang et al. and Choi et al., who achieved reduction to $65 \%$ and $75 \%$ of total duration, respectively [11,24]. It is reported that microwave heating prevented skin core formation [30]. The CFs demonstrated tensile strength as high as $2.6 \mathrm{GPa}$ (slightly higher than the CFs manufactured by the conventional process), a value that satisfies the demands of the automobile industry [20]. Musiol and Szatkowski et al. concluded that mass loss was connected to attributes that influence the improvement of tensile modulus, similarly to Fraczek-Szczypta and Bogun et al. [12]. Reduction up to 50\% in mass loss during stabilization is connected with a reduction in the crystallite size during carbonization, which is encouraging for effective reduction in stabilization duration.

Comparable performance of CFs was reported by Jo and Yoo et al. that utilized UV irradiation during stabilization with duration as low as $30 \mathrm{~min}$ - similar impact to the Choi et al. investigation of plasma-assisted stabilization-to stabilize textile-grade PAN. No photo-initiator was required, while temperature varied during treatment between the range of as low as $75-200{ }^{\circ} \mathrm{C}$. The derived $\mathrm{CFs}$ demonstrated tensile strength of $2.43 \mathrm{GPa}$ and tensile modulus as high as $195 \mathrm{GPa}$ [13]. Thus, irradiation heat treatment seems to effectively deal with the time-consuming stabilization of textile-grade PAN and tackle inhibition of stabilization induced by its composition due to sodium salt of acrylamidomethyl propane sulfonic acid (SAMPS) and sodium methallyl sulfonate (SMS) presence; it is typically consisted by $85 \%$ AN, and other monomers, mainly MA or a combination of VA, MMA, SMS, SAMPS, SSS, SMPE, IA [24].

Regarding costly equipment for $\gamma$-rays irradiation and possible safety requirements to enhance in-line applicability, low energy consumption in the range of $100-400 \mathrm{kGy}$ is the main strength. Zhao et al. demonstrated the in-line involvement of $\gamma$-rays following heat treatment for equal duration of $1 \mathrm{~h}$ each, but productivity was low [111]. However, the high values of tensile strength at $4.3 \mathrm{GPa}$ and Young modulus of $245 \mathrm{GPa}$ may arouse the interest in this approach. Kyoung et al. proposed electron beam irradiation (EBI) as a method for improving the stabilization of PAN fibers [122]. By applying EBI on PAN fibers radical generation is expected, which remain trapped until conventional heat treatment. The released radicals induce rapid structural transformation to polyene structure and promote cyclization [37]. The stabilization index was calculated by XRD and reached a value of $99.2 \%$ for EBI stabilized PAN fibers at $250{ }^{\circ} \mathrm{C}$ for $40 \mathrm{~min}$ [101]. The cross section of CFs exhibited a defect-free morphology and the tensile strength reached the value of $2.3 \mathrm{GPa}$. Additionally, Choi et al. reported coupling of EBI with conventional stabilization at 200-1500 kGy dosages [24], while even less energy output was found to be beneficial for cyclization between 400 and $800 \mathrm{kGy}$ as proposed by Cho et al. [25]. Further studies of EBI treatment lead to up to $75 \%$ savings regarding processing time (less than $40 \mathrm{~min})$, and energy $\left(\mathrm{T}<60^{\circ} \mathrm{C}\right)$ achieving $\mathrm{CFs}$ with tensile strength of $1.83 \mathrm{GPa}$ and modulus of 147 GPa [24,37]. EBI has also being characterized as cold stabilization by Cho et al. concerning 
effectiveness even at room temperature, accompanied with the observation that acidic comonomers do not participate at room temperature EBI-induced cyclization [25]. Thus, EBI treatment is considered as superior to irradiation species of UV, X-rays, $\gamma$-rays [37].

Amongst the highlights of stabilization proceedings, Park et al. materialized a rapid stabilization treatment with as low as $200 \mathrm{kGy}$ output and total duration of $13.3 \mathrm{~min}$ by coupling EBI (10 min) with Plasma assisted thermal treatment $(3.3 \mathrm{~min})$. The engineering behind this discovery was to use both diffusive and reactive oxygen species. It is well understood that plasma and EBI oxygen radical groups have significantly smaller radius than molecular oxygen of the conventional process, which favors penetration across the radial direction and all dehydrogenation, cyclization, and oxidation is accelerated [37,40]. Mechanical properties reached the values of $2.4 \mathrm{GPa}$ for tensile strength, while Young modulus was $196.3 \mathrm{GPa}$ after this rapid process [40].

The pros and cons for some of the most recent proposed modifications are presented through the Radar graph in Figure 7. Conventional thermal stabilization treatment seems wasteful as it is both energy- and time-consuming. It is clear that all the proposed improvements on the thermal oxidative process have their merits; however, their application on an industrial scale is to be decided by the cost-effectiveness of each method.

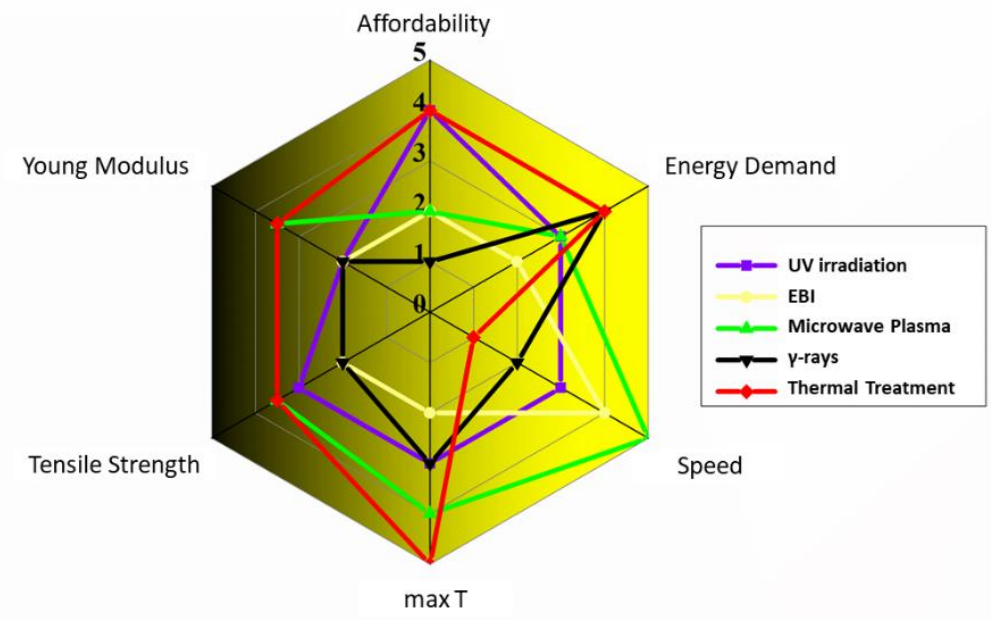

Figure 7. Comparison of the oxidation technologies for preparation of high-performance CFs.

\subsection{Carbonization Effect on Carbon Fiber Performance}

Carbonization handling is essential to obtain high performance CFs. It has been reported that high strength $\mathrm{CFs}$ are obtained when carbonization temperature rises to $1500{ }^{\circ} \mathrm{C}$ [14] for relatively high N/C ratio; this indicates sensitivity and necessity to precisely control the dwelling time above $700{ }^{\circ} \mathrm{C}$ to manipulate denitrogenation yield [11]. Further elevation of treatment temperature above $1500^{\circ} \mathrm{C}$ leads to a decrease in tensile strength and linear increase in the Young modulus. Modulus of elasticity increase is attributed by Tanaka et al. to slide-lock of the entangled junctions among the loosely compacted crystallites, while decrease in tensile strength can be ascribed to the increased crystallite size, nano-scale defects, and deteriorated orientation of crystallites in the core region of CF [8], which is not in accordance with Qian et al. who reported no actual relation [98]. It was also reported by Musiol and Szatkowski et al., that low temperature carbonization does not provide any benefit considering that crosslinking hinders crystallization, while the increase in temperature leads to increment of microstructure heterogeneity [14].

The investigation of literature data for tensile strength and modulus alternation with maximum carbonization temperature can be seen in Figures 8 and 9.

The variation in properties (Figures 8 and 9) of synthesized CFs at the same maximum temperature of carbonization is affected by cyclization and oxidation progress. This is confirmed by observing the data in supplementary information. Stabilization above $300^{\circ} \mathrm{C}$ has a negative impact on mechanical 
performance of CFs. Secondly, the increase in residence period in the maximum carbonization temperature, leads to the elevation of mechanical properties as supported by the detailed information included in supplementary information. However, microwave plasma carbonization seems to have an important role in efficient heat dissipation, and possibly in crystallite size, which has a critical impact to the synthesis of HSCFs or UHMCFs.

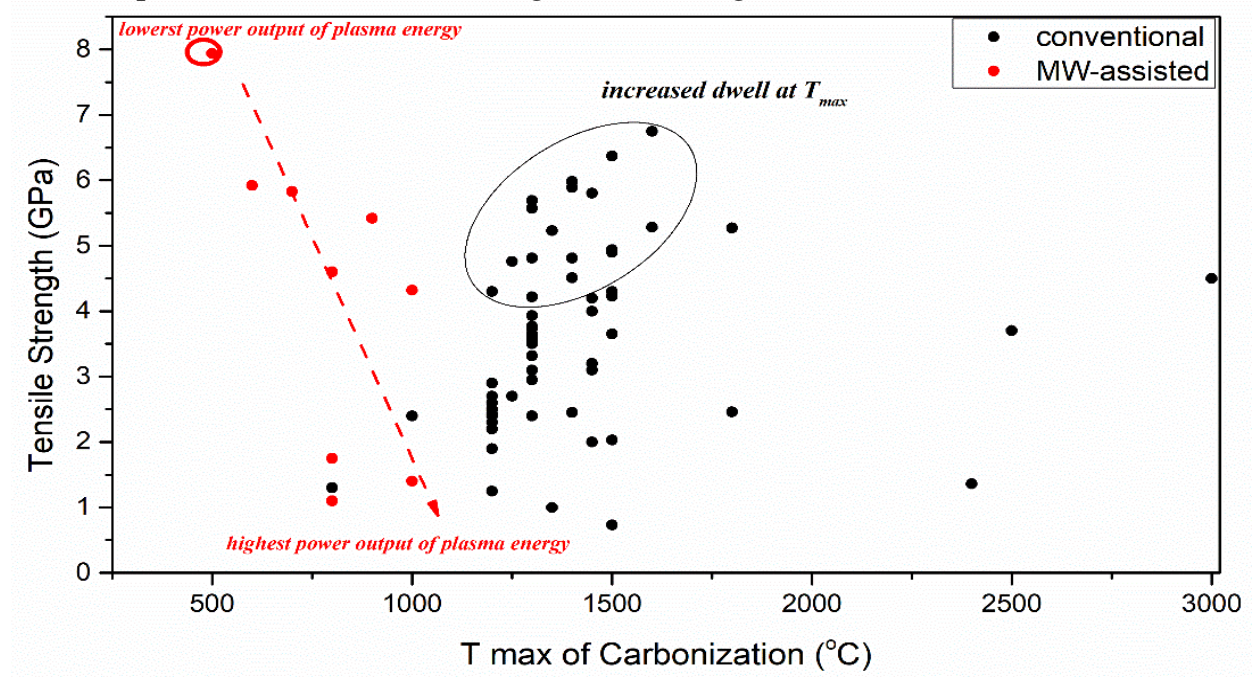

Figure 8. Dependence of Tensile strength on maximum temperature of carbonization based on literature data presented in Figure 3.

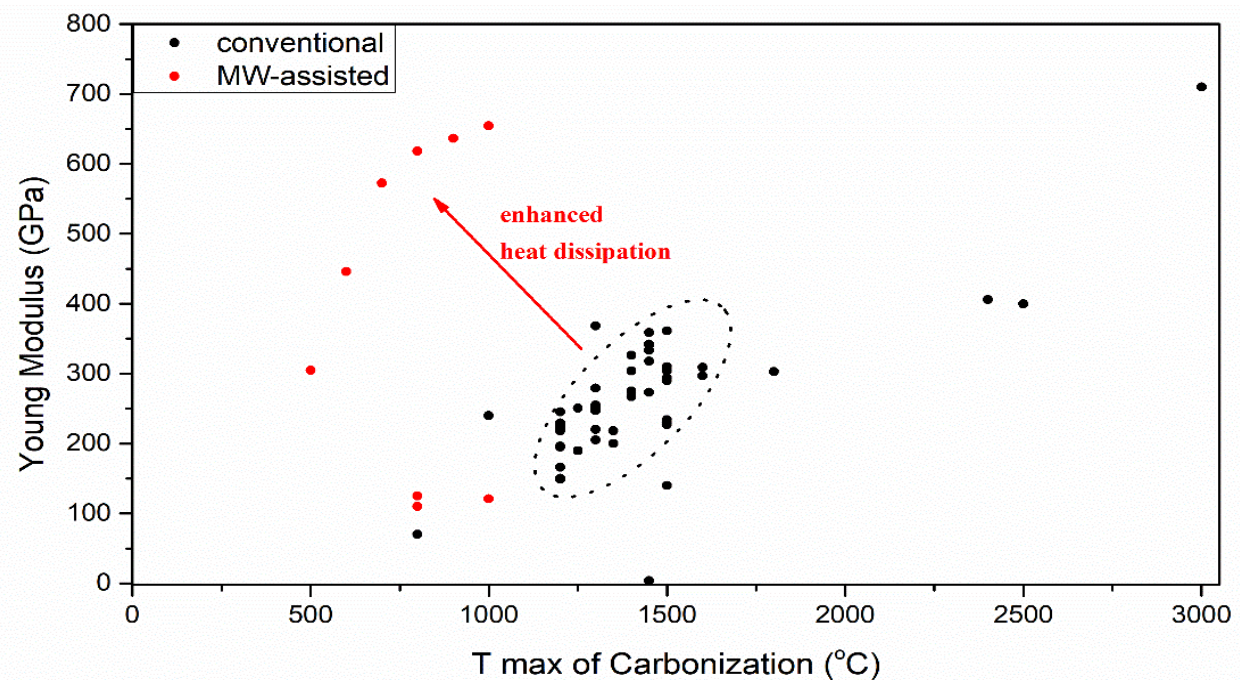

Figure 9. Dependence of Young modulus on maximum temperature of carbonization based on literature data presented in Figure 3.

In this direction a single-/multi-step microwave plasma carbonization process, has been suggested as a method that can both enhance the mechanical properties of the CFs and reduce the energy consumption [123]. Preliminary research efforts provided evidence that a two-step treatment could lead to up to $170 \%$ improvement in tensile strength, derived by the influence of both low power and high-power treatment [123]. So, Young et al. investigated this method and compared CFs by conventional carbonization to microwave plasma. Higher surface roughness after plasma process with no decrease in mechanical performance regarding conventional CFs is beneficial for mechanical interlocking of resin and CFs interface. As a result, microwave plasma carbonization is a promising candidate for next-generation carbonization $[24,123]$. 
Plain microwave furnace (max frequency output: $2.45 \mathrm{GHz}$, max power output: 100-1000 W) was used by Liu et al. and proposed advances in low-temperature carbonization in nitrogen and vacuum-assisted atmosphere [130]. Outstanding mechanical properties are reported at as low as $500{ }^{\circ} \mathrm{C}$ with tensile strength approaching $8 \mathrm{GPa}$ and Young modulus $305 \mathrm{GPa}$, while increase in temperature led to deterioration of tensile strength and elevation of Young modulus up to $655 \mathrm{GPa}$ at $1000^{\circ} \mathrm{C}$. These properties were achieved due to ion bombardment that reduced significantly defective regions [130]. Similarly, a highly appreciated approach to reduce defects on CFs during stabilization and carbonization is magnetic field application; the tensile strength of $\mathrm{CFs}$ by heat-treatment at $1500^{\circ} \mathrm{C}$ increased up to approximately $1 \mathrm{GPa}$, regardless of the values of the imposed tension [124]. Doping in Boron atmosphere has also been proposed to enhance tensile modulus, but this requires special control and higher temperature of processing (up to $1800^{\circ} \mathrm{C}$ ) to reach maximum tensile strength [11]; the improvement in mechanical properties over the conventionally carbonized fibers was not high enough to justify such an increase in complexity.

A Radar graph is intended to ease decision making by summarizing the impact of the most referenced carbonization approaches (Figure 10). Carbonization seems to be the process with the lowest potential for short-term improvements, but has the most significant impact on the mechanical properties. There is quite promising feedback from results derived by microwave coupling.

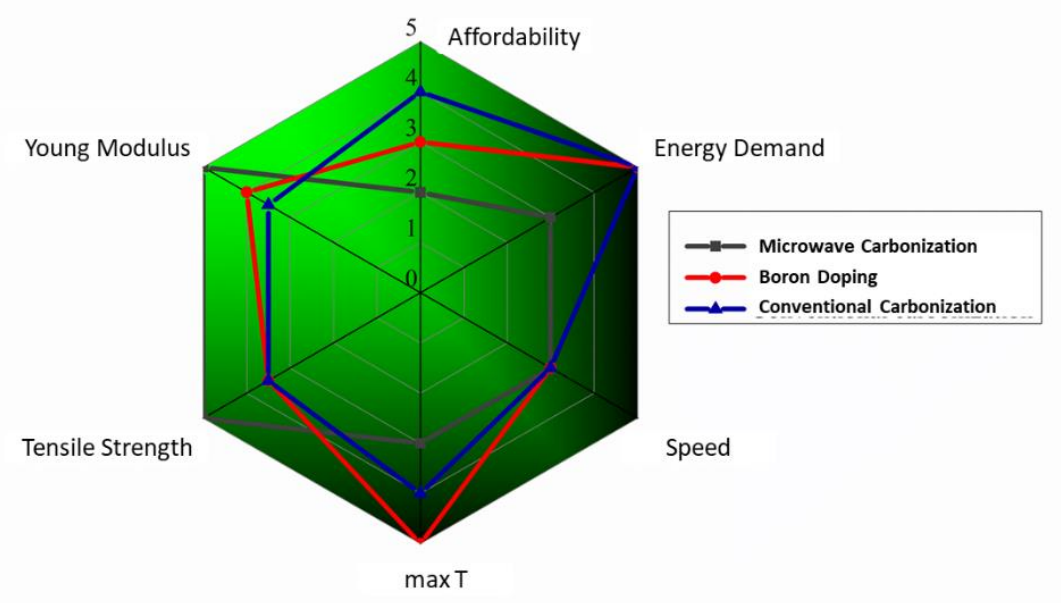

Figure 10. Carbonization technologies involved in high strength and high modulus CF synthesis.

\section{Conclusions and Outlook}

The effect of PAN structure on the stabilization is reviewed, and attention is mainly paid to the effect of molecular weight and of polymer stereochemical structure. The use of PAN with high $\mathrm{M}_{\mathrm{W}}$ and low PDI enhances rheological behavior of the spinning dope, and its contribution to stabilization treatment is major as soon as physical structure and morphology of the spun PAN fibers is ultimately improved. It is argued that tacticity seems to have a limited impact on the structure of the ladder polymer, but it also appears to affect significantly the reaction kinetics. Whereas, the effect of PAN stereochemical structure on stabilization is not yet completely clarified it retains scientific interest. Subsequently, the effect of oxidative stabilization on the thermomechanical properties was demonstrated and how the latter can be correlated with structural changes. Furthermore, aspects for interpretation of novel features in CF manufacturing are realized by extensive discussion in structure-property relations to enable purposeful developments in industry.

The in-depth knowledge of PAN transformation to CFs is a major step towards the involvement of lower quality PAN precursors with higher comonomer content or lower $\mathrm{M}_{\mathrm{w}}$, which both determine the precursor cost, the spinning technique and the requirement of solvents (wet or melt spinning). Operation conditions to aim the features of high-quality precursors after processing is key to access the market. Documentation of critical changes in the thermomechanical properties during the 
progress of stabilization can be precious. Establishing a novel process is often concerned with how the gradual transformation of PAN copolymer structure from thermoplastic to ladder polymer can be influenced from the polymer transitions. These variables are favorably affected by chemical composition. Promising advances on modifying the stabilization process are presented; the focus is on reducing treatment duration and energy consumption through advanced irradiation procedures such as microwave plasma and EBI. Optimization of stabilized structure is on target, as this is the preparative step to determine the orientation of turbostatic graphitic planes during carbonization. Moreover, it is essential to acknowledge current carbonization approaches in order to identify key features. In this review it was demonstrated that improved heat dissipation during carbonization was favored by adopting alternative technologies involving irradiation during stabilization and carbonization. This is essential to achieve better structural conformation of CFs to advance mechanical properties, and especially Young Modulus, in order to better commercialize the technology over time. Still, there is a huge gap in fulfilling the bottom-up expectations of massive carbon bond strength to be macroscopically translated and emerge in a product with exceptional mechanical performance. Evolution of $\mathrm{CF}$ technology will enable widespread application in the fields of automotive, aeronautics and space infrastructure.

Author Contributions: Conceptualization, S.S., E.P.K. and G.K.; Methodology, S.S., E.P.K. and G.K.; Formal Analysis, S.S., E.P.K. and G.K.; Investigation, S.S. and G.K.; Resources, C.A.C., E.P.K.; Data Curation, E.P.K. and G.K.; Writing-Original Draft Preparation, C.A.C., E.P.K., G.K., and S.S.; Writing-Review and Editing, C.A.C., E.P.K., G.K., and S.S.; Visualization, C.A.C., E.P.K. and G.K.; Supervision, C.A.C., E.P.K., S.S., and G.K.; Project Administration, C.A.C., E.P.K.; Funding Acquisition, C.A.C., E.P.K. All authors have read and agreed to the published version of the manuscript.

Funding: This work has partially received funding from the EU FP7 Project "Functionalized Innovative Carbon Fibres Developed from Novel Precursors with Cost Efficiency and Tailored Properties" (FIBRALSPEC) under Grant Agreement No. 604248.

Conflicts of Interest: The authors declare no conflict of interest.

\section{Appendix A Appendix}

\section{Physical Structure of PAN Fibers}

A crucial point in conventionally adopted wet spinning process is to keep the polymer into transitional gel-like phase and avoid the abrupt elastoplastic transition. Remaining in the viscoplastic state permits higher elongation of fibers inside coagulation bath, which is termed as jet stretch. There are mainly two reasons for this prerequisite; firstly, it is difficult to extend the PAN during transition to elastoplastic state, since there is limited mobility. Secondly, PAN is impermeable to water vapour $\left(18.4 \cdot 10^{-10} \mathrm{~g} \cdot \mathrm{cm}^{-1} \cdot \mathrm{s}^{-1} \cdot \mathrm{bar}^{-1}\right.$ at $\left.25^{\circ} \mathrm{C}\right)$ [131]; should coagulation be rapid, then an outer thin layer is formed that hinders diffusion. Coagulation of inner structure results in radially heterogeneity known as skin-core effect $[10,47]$. Theoretically, higher values of jet stretch may induce more uniform cross section and fewer defects.

Detailed investigations showed that there could be as many as four different layers across the cross section of a PAN filament, each layer having different crystalline content and degree of orientation $[10,48]$. The cross section quality of PAN fibers depends heavily on the temperature of the coagulation solution and increased uniformity is connected to hot bath processing. Nevertheless, voids can be generated [4]. In the case of DMSO baths and at low ratio of solvent, a kidney-like shaped cross section and skin-core structure are developed, while crystallinity is lowered. Hence, PAN fibers are usually spun in 65-70 wt\% DMSO coagulation bath [22,132].

Often during the coagulation of PAN a fibrillar network with relatively high void concentration is formed [133]. Progressive removal of these voids is performed by post-spinning, which is beneficial for improvement in crystallinity and orientation degree [134]. Drawing comprises of various stages, where the fibers are heated above their transition temperature and stretched up to $1000 \%$. This is enabled by the increased segmental mobility of PAN macromolecules. The most common heating 
mediums are the steam and hot water. The hot drawing step improves also the orientation of the fibers and is often solvent or steam-assisted in the temperature range of $90-180^{\circ} \mathrm{C}$ under neutral or mild acidic conditions ( $\mathrm{pH}>3.5$ ) $[11,13,14,19]$. The manufacturers of PAN-based CFs rely heavily on drawing processing in order to improve mechanical properties $[4,19]$. In highly oriented PAN monofilaments a rough external surface and channels were induced by the collapse and densification of the fibrillar network after a series of heat treatment up to $160{ }^{\circ} \mathrm{C}$ [20].

A similar morphology that combines defect-free cross section and rough external surface was also observed in the case of fibers wet spun from a PAN copolymer with MMA. When stretching degree decreased, roughness and mechanical properties followed the same trend [65]. The use of rather large amount of comonomers seems to distort the structure of the ordered regions. The main d-spacing from 5.15 tends to increase at about $5.30 \AA$, which probably causes considerable decrease of the dipole-dipole interactions in amorphous regions. Therefore, fusion of both the polymer transitions is observed at lower temperature compared to homopolymer PAN [114], as in case of 15\% replacement of AN with a monomer as MA or VA [13]. However, copolymer fibers with $4 \mathrm{~mol} \% \mathrm{MMA}$ as determined by NMR, demonstrated pretty impressive values of crystallinity up to $80 \%$ at high drawing ratio, alongside with preferred orientation of $87 \%$ and crystallite length $8.5 \mathrm{~nm}$. At low ratios these values somewhat decreased to $75 \%, 84 \%$ and $6.3 \mathrm{~nm}$, respectively [65].

The hexagonal mesophase structure has been confirmed by HRTEM measurements of PAN fibers $[49,93,94]$. The study of the ordered regions showed that mesophase domains were large enough in the transverse cross section of the fibers forming circular domains with diameter around 50-100 nm. However, in the longitudinal cross section the mesophase domains were bundle-like with a length around 5-10 nm, and formed a maze-like structure [94]. The rather small angle of around 20 (2D ss NMR) between adjacent CN groups in a macromolecule for the atactic PAN has been described as the source for the appearance of lateral ordering of atactic PAN fibers, despite the intensive steric hindrances. HRTEM demonstrated that the ordered structures are not uniformly distributed along the fiber axis, but are mainly concentrated in the outer layers (skin-core phenomenon), while inner layers contain more amorphous areas and voids [48].

On the other hand, the effect of the sequence distribution on the physical structure has not been extensively investigated. In a study, PAN copolymers with IA were synthesized by RAFT with different comonomer distributions such as random, block, etc., and block copolymer demonstrated the highest crystallite size [95]. Furthermore, by comparing the films from PAN with different tacticity, it was found that the crystalline content depends only slightly on whether the polymer is isotactic or atactic [135]. However, the crystallite size is substantially higher in the case of isotactic PAN [57]. These results indicate that crystalline structure of PAN depends strongly on manufacturing process, which was evidenced in case of P(AN@MMA) copolymer. However, chemistry is important to improve spinnability, as in case of gel-spun high-M $\mathrm{M}_{\mathrm{W}}$ PAN, with crystallinity reaching $64 \%$ and crystallite length of $15.7 \mathrm{~nm}$ [120].

\section{References}

1. Bajaj, P.; Roopanwal, A.K. Thermal Stabilization of Acrylic Precursors for the Production of Carbon Fibers: An Overview. J. Macromol. Sci. Part C Polym. Rev. 1997, 37, 97-147. [CrossRef]

2. Peebles, L.H. Carbon Fibers Formation, Structure, and Properties; Group, T.F., Ed.; CRC Press: 6000 Broken Sound Parkway NW, Boca Raton, Suite 300, FL, USA, 1995.

3. Manocha, L.M. Carbon Fibers. In Reference Module in Materials Science and Materials Engineering, Encyclopedia of Materials: Science and Technology, 2nd ed.; Elsevier: Amsterdam, The Netherlands, 2001; pp. 906-916. [CrossRef]

4. Kaur, J.; Millington, K.; Smith, S. Producing high-quality precursor polymer and fibers to achieve theoretical strength in carbon fibers: A review. J. Appl. Polym. Sci. 2016, 133. [CrossRef]

5. Liu, Y.; Kumar, S. Recent Progress in Fabrication, Structure, and Properties of Carbon Fibers. Polym. Rev. 2012, 52, 234-258. [CrossRef]

6. Newcomb, B.A. Processing, structure, and properties of carbon fibers. Compos. Part A Appl. Sci. Manuf. 2016, 91, 262-282. [CrossRef] 
7. Sidorina, A.I.; Gunyaeva, A.G. Market for Carbon Fibres and Composites Based on them. A review. Fibre Chem. 2017, 48, 306-310. [CrossRef]

8. Tanaka, F.; Okabe, T. Historical Review of Processing, Microstructures, and Mechanical Properties of PAN-Based Carbon Fibers. Ref. Modul. Mater. Sci. Mater. Eng. 2018, 66-85. [CrossRef]

9. Xu, Z.; Gao, C. Graphene fiber: A new trend in carbon fibers. Mater. Today 2015, 18, 480-492. [CrossRef]

10. Nunna, S.; Naebe, M.; Hameed, N.; Fox, B.L.; Creighton, C. Evolution of radial heterogeneity in polyacrylonitrile fibres during thermal stabilization: An overview. Polym. Degrad. Stab. 2017, 136, 20-30. [CrossRef]

11. Huang, X. Fabrication and Properties of Carbon Fibers. Materials 2009, 2, 2369-2403. [CrossRef]

12. Fraczek-Szczypta, A.; Bogun, M.; Blazewicz, S. Carbon fibers modified with carbon nanotubes. J. Mater. Sci. 2009, 44, 4721-4727. [CrossRef]

13. Jo, A.Y.; Yoo, S.H.; Chung, Y.-S.; Lee, S. Effects of ultraviolet irradiation on stabilization of textile-grade polyacrylonitrile fibers without photo-initiator for preparing carbon fibers. Carbon 2019, 144, 440-448. [CrossRef]

14. Musiol, P.; Szatkowski, P.; Gubernat, M.; Weselucha-Birczynska, A.; Blazewicz, S. Comparative study of the structure and microstructure of PAN-based nano- and micro-carbon fibers. Ceram. Int. 2016, 42, 11603-11610. [CrossRef]

15. Santhana Krishnan, G.; Thomas, P.; Naveen, S.; Murali, N. Molecular and thermal studies of carbon fiber precursor polymers with low thermal-oxidative stabilization characteristics. J. Appl. Polym. Sci. 2018, 135, 46381. [CrossRef]

16. Deurbergue, A.; Oberlin, A. Stabilization and carbonization of pan-based carbon fibers as related to mechanical properties. Carbon 1991, 29, 621-628. [CrossRef]

17. Kim, J.W.; Lee, J.S. Preparation of carbon fibers from linear low density polyethylene. Carbon 2015, 94, 524-530. [CrossRef]

18. De Palmenaer, A.; Wortberg, G.; Drissen, F.; Seide, G.; Gries, T. Production of Polyethylene Based Carbon Fibres. Chem. Eng. Trans. 2015, 43, 1699-1704. [CrossRef]

19. Meinl, J.; Schönfeld, K.; Kirsten, M.; Kittler, K.; Michaelis, A.; Cherif, C. Optimization of the temperature program to scale up the stabilization of polyacrylonitrile fibers. Compos. Part A Appl. Sci. Manuf. 2017, 96, 37-45. [CrossRef]

20. Kim, S.-Y.; Lee, S.; Park, S.; Jo, S.M.; Lee, H.-S.; Joh, H.-I. Continuous and rapid stabilization of polyacrylonitrile fiber bundles assisted by atmospheric pressure plasma for fabricating large-tow carbon fibers. Carbon 2015, 94, 412-416. [CrossRef]

21. Henrici-Olivé, G.; Olivé, S. The chemistry of carbon fiber formation from polyacrylonitrile. Ind. Dev. 1983, 51, 1-60. [CrossRef]

22. Peng, G.-Q.; Zhang, X.-H.; Wen, Y.-F.; Yang, Y.-G.; Liu, L. Effect of Coagulation Bath DMSO Concentration on the Structure and Properties of Polyacrylonitrile (PAN) Nascent Fibers during Wet-Spinning. J. Macromol. Sci. Part B 2008, 47, 1130-1141. [CrossRef]

23. Hao, J.; Liu, Y.; Lu, C. Effect of acrylonitrile sequence distribution on the thermal stabilization reactions and carbon yields of poly(acrylonitrile-co-methyl acrylate). Polym. Degrad. Stab. 2018, 147, 89-96. [CrossRef]

24. Choi, D.; Kil, H.-S.; Lee, S. Fabrication of low-cost carbon fibers using economical precursors and advanced processing technologies. Carbon 2019, 142, 610-649. [CrossRef]

25. Cho, D.W.; Ghorpade, R.V.; Hong, S.C. Identifying the role of the acidic comonomer in poly(acrylonitrileco -itaconic acid) during stabilization process through low temperature electron beam irradiation. Polym. Degrad. Stab. 2018, 153, 220-226. [CrossRef]

26. Cai, J.Y.; McDonnell, J.; Brackley, C.; O’Brien, L.; Church, J.S.; Millington, K.; Smith, S.; Phair-Sorensen, N. Polyacrylonitrile-based precursors and carbon fibers derived from advanced RAFT technology and conventional methods-The 1st comparative study. Mater. Today Commun. 2016, 9, 22-29. [CrossRef]

27. Arbab, S.; Zeinolebadi, A. Quantitative analysis of the effects of comonomers and heating conditions on the stabilization reactions of polyacrylonitrile fibers as carbon fiber precursors. Polym. Degrad. Stab. 2017, 139, 107-116. [CrossRef]

28. Bashir, Z. A critical review of the stabilisation of polyacrylonitrile. Carbon 1991, 29, 1081-1090. [CrossRef]

29. Guo, X.; Cheng, Y.; Fan, Z.; Feng, Z.; He, L.; Liu, R.; Xu, J. New insights into orientation distribution of high strength polyacrylonitrile-based carbon fibers with skin-core structure. Carbon 2016, 109, 444-452. [CrossRef] 
30. Liu, J.; Xiao, S.; Shen, Z.; Xu, L.; Zhang, L.; Peng, J. Study on the oxidative stabilization of polyacrylonitrile fibers by microwave heating. Polym. Degrad. Stab. 2018, 150, 86-91. [CrossRef]

31. Zhang, C.; Liu, J.; Guo, S.; Xiao, S.; Shen, Z.; Xu, L. Comparison of microwave and conventional heating methods for oxidative stabilization of polyacrylonitrile fibers at different holding time and heating rate. Ceram. Int. 2018, 44, 14377-14385. [CrossRef]

32. Morris, E.A.; Weisenberger, M.C.; Abdallah, M.G.; Vautard, F.; Grappe, H.; Ozcan, S.; Paulauskas, F.L.; Eberle, C.; Jackson, D.; Mecham, S.J.; et al. High performance carbon fibers from very high molecular weight polyacrylonitrile precursors. Carbon 2016, 101, 245-252. [CrossRef]

33. Nunna, S.; Naebe, M.; Hameed, N.; Creighton, C.; Naghashian, S.; Jennings, M.J.; Atkiss, S.; Setty, M.; Fox, B.L. Investigation of progress of reactions and evolution of radial heterogeneity in the initial stage of thermal stabilization of PAN precursor fibres. Polym. Degrad. Stab. 2016, 125, 105-114. [CrossRef]

34. Nunna, S.; Creighton, C.; Hameed, N.; Naebe, M.; Henderson, L.C.; Setty, M.; Fox, B.L. Radial structure and property relationship in the thermal stabilization of PAN precursor fibres. Polym. Test. 2017, 59, $203-211$. [CrossRef]

35. Jain, M.J.; Abhiraman, A.S. Conversion of acrylonitrile-based precursors to carbon fibres. Part 2. Precursor morphology and thermooxidative stabilization. Composites 1987, 18, 263. [CrossRef]

36. Gupta, A.K.; Paliwal, D.K.; Bajaj, P. Acrylic Precursors for Carbon Fibers. Polym. Rev. 1991, 31, 1-89. [CrossRef]

37. Zhang, W.; Wang, M.; Zhang, W.; Liu, W.; Yang, C.; Shen, R.; Wu, G. Significantly reduced pre-oxidation period of PAN fibers by continuous electron beam irradiation: Optimization by monitoring radical variation. Polym. Degrad. Stab. 2018, 158, 72-82. [CrossRef]

38. Chung, D. Carbon Fiber Composites, 1st ed.; Butterworth-Heinmann: Boston, MA, USA, 2012.

39. Liu, J.; Wang, P.H.; Li, R.Y. Continuous carbonization of polyacrylonitrile-based oxidized fibers: Aspects on mechanical properties and morphological structure. J. Appl. Polym. Sci. 1994, 52, 945-950. [CrossRef]

40. Park, S.; Kil, H.-S.; Choi, D.; Song, S.-K.; Lee, S. Rapid stabilization of polyacrylonitrile fibers achieved by plasma-assisted thermal treatment on electron-beam irradiated fibers. J. Ind. Eng. Chem. 2019, 69, 449-454. [CrossRef]

41. Newcomb, B.A.; Giannuzzi, L.A.; Lyons, K.M.; Gulgunje, P.V.; Gupta, K.; Liu, Y.; Kamath, M.; McDonald, K.; Moon, J.; Feng, B.; et al. High resolution transmission electron microscopy study on polyacrylonitrile/carbon nanotube based carbon fibers and the effect of structure development on the thermal and electrical conductivities. Carbon 2015, 93, 502-514. [CrossRef]

42. Jäger, H.; Cherif, C.; Kirsten, M.; Behnisch, T.; Wolz, D.S.; Böhm, R.; Gude, M. Influence of processing parameters on the properties of carbon fibres-An overview. Mater. Und Werkst. 2016, 47, 1044-1057. [CrossRef]

43. Chand, S. Review Carbon Fibers for Composites. J. Mater. Sci. 2000, 35, 1303-1313. [CrossRef]

44. Xue, T.J.; McKinney, M.A.; Wilkie, C.A. The thermal degradation of polyacrylonitrile. Polym. Degrad. Stab. 1997, 58, 193-202. [CrossRef]

45. Vasishtha, R.; Srivastava, A.K. Polymerization of methacrylic acid and acrylonitrile by p-nitrobenzyl triphenyl phosphonium ylide. Polym. Eng. Sci. 1991, 31, 567-570. [CrossRef]

46. Acrylonitrile Polymers. In Van Nostrand's Scientific Encyclopedia; Considine, G.D. (Ed.) John Wiley \& Sons, Inc.: Hoboken, NJ, USA, 2006. [CrossRef]

47. Kricheldorf, H.R.; Nuyken, O.; Swift, G. Handbook of Polymer Synthesis, 2nd ed.; Marcel Dekker: New York, NY, USA, 2005.

48. Ge, H.; Liu, H.; Chen, J.; Wang, C. The skin-core structure of poly(acrylonitrile-itaconic acid) precursor fibers in wet-spinning. J. Appl. Polym. Sci. 2008, 108, 947-952. [CrossRef]

49. Yu, M.; Wang, C.; Bai, Y.; Zhu, B.; Ji, M.; Xu, Y. Microstructural evolution in polyacrylonitrile fibers during oxidative stabilization. J. Polym. Sci. Part B Polym. Phys. 2008, 46, 759-765. [CrossRef]

50. Olabisi, O.; Adewale, K. Handbook of Thermoplastics, 2nd ed.; CRC Press: Boca Raton, FL, USA, 2015.

51. Fu, Z.; Liu, B.; Deng, Y.; Ma, J.; Cao, C.; Wang, J.; Ao, Y.; Zhang, H. The suitable itaconic acid content in polyacrylonitrile copolymers used for PAN-based carbon fibers. J. Appl. Polym. Sci. 2016, 133. [CrossRef]

52. Jiang, J.; Lu, X.; Lu, Y. Preparation of polyacrylonitrile with improved isotacticity and low polydispersity. J. Appl. Polym. Sci. 2010. [CrossRef]

53. Soulis, S.; Anagnou, S.; Milioni, E.; Mpalias, C.; Kartsonakis, I.A.; Kanellopoulou, I.; Markakis, V.; Koumoulos, E.P.; Kontou, E.; Charitidis, C.A. Strategies towards Novel Carbon Fiber Precursors: The Research Results on the Synthesis of PAN Copolymers via AGET ATRP and on Lignin as a Precursor. NanoWorld J. 2015, 1. [CrossRef] 
54. Niu, T.; Jiang, J.; Li, S.; Ni, B.; Liu, X.; Chen, M. Well-Defined High-Molecular-Weight Polyacrylonitrile Formation via Visible-Light-Induced Metal-Free Radical Polymerization. Macromol. Chem. Phys. 2017, 218, 1700169. [CrossRef]

55. Hao, J.; Li, W.; Suo, X.; Wei, H.; Lu, C.; Liu, Y. Highly isotactic ( $>60 \%)$ polyacrylonitrile-based carbon fiber: Precursor synthesis, fiber spinning, stabilization and carbonization. Polymer 2018, 157, 139-150. [CrossRef]

56. Krishnan, G.S.; Burkanudeen, A.; Murali, N.; Phadnis, H. Eco-friendly synthesis of carbon fiber precursor polymers and their molecular characteristics. Green Chem. 2012, 14, 1778. [CrossRef]

57. Ghorpade, R.V.; Cho, D.W.; Hong, S.C. Effect of controlled tacticity of polyacrylonitrile (co)polymers on their thermal oxidative stabilization behaviors and the properties of resulting carbon films. Carbon 2017, 121, 502-511. [CrossRef]

58. Morris, E.A.; Weisenberger, M.C.; Bradley, S.B.; Abdallah, M.G.; Mecham, S.J.; Pisipati, P.; McGrath, J.E. Synthesis, spinning, and properties of very high molecular weight poly(acrylonitrile- co -methyl acrylate) for high performance precursors for carbon fiber. Polymer 2014, 55, 6471-6482. [CrossRef]

59. Hatada, K.; Kitayama, T. NMR Spectroscopy of Polymers; Springer: Berlin/Heidelberg, Germany, 2004.

60. Katsuraya, K.; Hatanaka, K.; Matsuzaki, K.; Minagawa, M. Assignment of finely resolved 13 C NMR spectra of polyacrylonitrile. Polymer 2001, 42, 6323-6326. [CrossRef]

61. Santhana Krishnan, G.; Burkanudeen, A.; Murali, N.; Phadnis, H. Facile synthesis of stereoregular carbon fiber precursor polymers by template assisted solid phase polymerization. Express Polym. Lett. 2012, 6, 729-738. [CrossRef]

62. Rwei, S.-P.; Way, T.-F.; Chiang, W.-Y.; Pan, S.-Y. Effect of tacticity on the cyclization of polyacrylonitrile copolymers. Colloid Polym. Sci. 2017, 295, 803-815. [CrossRef]

63. Sawai, D.; Kanamoto, T.; Yamazaki, H.; Hisatani, K. Dynamic Mechanical Relaxations in Poly(acrylonitrile) with Different Stereoregularities. Macromolecules 2004, 37, 2839-2846. [CrossRef]

64. Banaie, K.A.; Mirjalili, M.; Eslami-Farsani, R. The study of the correlation between ascending and descending rates of the imposed specific stress and transposition of chemical reactions during PAN precursor fibers stabilization. Polym. Degrad. Stab. 2018, 156, 234-244. [CrossRef]

65. Spörl, J.M.; Ota, A.; Beyer, R.; Lehr, T.; Müller, A.; Hermanutz, F.; Buchmeiser, M.R. Carbon fibers prepared from tailored reversible-addition-fragmentation transfer copolymerization-derived poly (acrylonitrile)-co-poly(methylmethacrylate). J. Polym. Sci. Part A Polym. Chem. 2014, 52, 1322-1333. [CrossRef]

66. Hou, C.; Qu, R.; Qun, W.; Ying, L.; Wang, C. Degradation of acrylonitrile-ammonium itaconate copolymers. J. Appl. Polym. Sci. 2005, 98, 1708-1711. [CrossRef]

67. Wang, Y.X.; Liu, Y.L.; Wang, G.L.; Wang, L.M.; Wang, C.G. Aqueous deposited copolymerization of acrylonitrile with ammonium itaconate under magnetic field. J. Polym. Res. 2011, 18, 1323-1329. [CrossRef]

68. Krishnan, G.S. Pyrolysis and Thermal Stability of Carbon Fiber Polymer Precursors with Different Microstructures. Polym. Precursor-Deriv. Carbon 2014, 1173, 169-187. [CrossRef]

69. Kaji, H.; Schmidt-Rohr, K. Conformation and Dynamics of Atactic Poly(acrylonitrile). 3. Characterization of Local Structure by Two-Dimensional2H-13C Solid-State NMR. Macromolecules 2001, 34, 7382-7391. [CrossRef]

70. Kaji, H.; Schmidt-Rohr, K. Conformation and Dynamics of Atactic Poly(acrylonitrile). 2. Torsion Angle Distributions in Meso Dyads from Two-Dimensional Solid-State Double-Quantum13C NMR. Macromolecules 2001, 34, 7368-7381. [CrossRef]

71. Coleman, M.M.; Sivy, G.T.; Painter, P.C.; Snyder, R.W.; Gordon, B. Studies of the degradation of acrylonitrile/acrylamide copolymers as a function of composition and temperature. Carbon 1983, 21, 255-267. [CrossRef]

72. Soulis, S.; Simitzis, J. Thermomechanical behaviour of poly[acrylonitrile-co-(methyl acrylate)] fibres oxidatively treated at temperatures up to $180^{\circ} \mathrm{C}$. Polym. Int. 2005, 54, 1474-1483. [CrossRef]

73. Wang, Y.; Xu, L.; Wang, M.; Pang, W.; Ge, X. Structural Identification of Polyacrylonitrile during Thermal Treatment by Selective 13C Labeling and Solid-State 13C NMR Spectroscopy. Macromolecules 2014, 47, 3901-3908. [CrossRef]

74. Liu, X.; Makita, Y.; Hong, Y.-L.; Nishiyama, Y.; Miyoshi, T. Chemical Reactions and Their Kinetics of atactic-Polyacrylonitrile As Revealed by Solid-State 13C NMR. Macromolecules 2016, 50, 244-253. [CrossRef]

75. Qin, X.; Lu, Y.; Xiao, H.; Hao, Y.; Pan, D. Improving preferred orientation and mechanical properties of PAN-based carbon fibers by pretreating precursor fibers in nitrogen. Carbon 2011, 49, 4598-4600. [CrossRef] 
76. Lei, S.; Wu, S.; Gao, A.; Cao, W.; Li, C.; Xu, L. The formation of conjugated structure and its transformation to pseudo-graphite structure during thermal treatment of polyacrylonitrile. High Perform. Polym. 2016, 29, 1097-1109. [CrossRef]

77. Watt, W.; Johnson, W. The Effect of Length Changes during the Oxidation of Polyacrylonitrile Fibers on the Young's Modulus of Carbon Fibers. Appl. Polym. Symp. 1969, 9, 215-227.

78. Bahl, O.P.; Mathur, R.B. Effect of load on the mechanical properties of carbon fibres from pan precursor. Fibre Sci. Technol. 1979, 12, 31-39. [CrossRef]

79. Sabet, E.N.; Nourpanah, P.; Arbab, S. A Novel Method for Investigation of Entropic Stress in Prestabilization of PAN-Based Precursor Fibers. Adv. Polym. Technol. 2017, 36, 424-432. [CrossRef]

80. Fitzer, E.; Frohs, W.; Heine, M. Optimization of stabilization and carbonization treatment of PAN fibres and structural characterization of the resulting carbon fibres. Carbon 1986, 24, 387-395. [CrossRef]

81. Kalashnik, A.; Panichkina, O.N.; Rudinskaya, G.Y.; Serkov, A.T. Shrinkage Mechanisms in Thermooxidative Stabilization of Acrylic Fibres. Fibre Chem. 2001, 33, 132-139. [CrossRef]

82. Simitzis, J.; Soulis, S. Correlation of chemical shrinkage of polyacrylonitrile fibres with kinetics of cyclization. Polym. Int. 2008, 57, 99-105. [CrossRef]

83. Yongping, H.; Tongqing, S.; Haojing, W.; Dong, W. Effect of Heating Rate on the Chemical Reaction during Stabilization of Polyacrylonitrile Fibers. Text. Res. J. 2008, 78, 806-811. [CrossRef]

84. Hou, Y.; Sun, T.; Wang, H.; Wu, D. A new method for the kinetic study of cyclization reaction during stabilization of polyacrylonitrile fibers. J. Mater. Sci. 2008, 43, 4910-4914. [CrossRef]

85. Hou, Y.; Sun, T.; Wang, H.; Wu, D. Thermal-shrinkage investigation of the chemical reaction during the stabilization of polyacrylonitrile fibers. J. Appl. Polym. Sci. 2009, 114, 3668-3672. [CrossRef]

86. Soulis, S.; Dragatogiannis, D.A.; Konstantopoulos, G.; Charitidis, C. Application of PAN fiber length change as the oxidative stabilization process control parameter. Mater. Today Proc. 2018, 5, 27645-27652. [CrossRef]

87. Sabet, E.N.; Nourpanah, P.; Arbab, S. Quantitative analysis of entropic stress effect on the structural rearrangement during pre-stabilization of PAN precursor fibers. Polymer 2016, 90, 138-146. [CrossRef]

88. Fazlitdinova, A.G.; Tyumentsev, V.A.; Podkopayev, S.A.; Shveikin, G.P. Changes of polyacrylonitrile fiber fine structure during thermal stabilization. J. Mater. Sci. 2010, 45, 3998-4005. [CrossRef]

89. Bashir, Z. The Hexagonal Mesophase in Atactic Polyacrylonitrile: A New Interpretation of the Phase Transitions in the Polymer. J. Macromol. Sci. Part B 2001, 40, 41-67. [CrossRef]

90. Suresh, K.I.; Thomas, K.S.; Rao, B.S.; Nair, C.P.R. Viscoelastic properties of polyacrylonitrile terpolymers during thermo-oxidative stabilization (cyclization). Polym. Adv. Technol. 2008, 19, 831-837. [CrossRef]

91. Sperling, L.H. Introduction to Physical Polymer Science, 4th ed.; Wiley-Interscience: New York, NY, USA, 2005.

92. Bashir, Z.; Rastogi, S. The Explanation of the Increase in Slope at the $\mathrm{Tg}$ in the Plot of d-Spacing Versus Temperature in Polyacrylonitrile. J. Macromol. Sci. Part B 2004, 44, 55-78. [CrossRef]

93. Bai, Y.-J.; Wang, C.-G.; Lun, N.; Wang, Y.-X.; Yu, M.-J.; Zhu, B. HRTEM microstructures of PAN precursor fibers. Carbon 2006, 44, 1773-1778. [CrossRef]

94. He, D.-X.; Wang, C.-G.; Bai, Y.-J.; Lun, N.; Zhu, B.; Wang, Y.-X. Microstructural evolution during thermal stabilization of PAN fibers. J. Mater. Sci. 2007, 42, 7402-7407. [CrossRef]

95. Nguyen-Thai, N.U.; Hong, S.C. Controlled architectures of poly(acrylonitrile-co-itaconic acid) for efficient structural transformation into carbon materials. Carbon 2014, 69, 571-581. [CrossRef]

96. Liu, Y.; Choi, Y.H.; Chae, H.G.; Gulgunje, P.; Kumar, S. Temperature dependent tensile behavior of gel-spun polyacrylonitrile and polyacrylonitrile/carbon nanotube composite fibers. Polymer 2013, 54, 4003-4009. [CrossRef]

97. Ogawa, H.; Saito, K. Oxidation behavior of polyacrylonitrile fibers evaluated by new stabilization index. Carbon 1995, 33, 783-788. [CrossRef]

98. Qian, X.; Zhi, J.; Chen, L.; Zhong, J.; Wang, X.; Zhang, Y.; Song, S. Evolution of microstructure and electrical property in the conversion of high strength carbon fiber to high modulus and ultrahigh modulus carbon fiber. Compos. Part A Appl. Sci. Manuf. 2018, 112, 111-118. [CrossRef]

99. Fochler, H.S.; Mooney, J.R.; Ball, L.E.; Boyer, R.D.; Grasselli, J.G. Infrared and NMR spectroscopic studies of the thermal degradation of polyacrylonitrile. Spectrochim. Acta Part A Mol. Spectrosc. 1985, 41, 271-278. [CrossRef]

100. Usami, T.; Itoh, T.; Ohtani, H.; Tsuge, S. Structural study of polyacrylonitrile fibers during oxidative thermal degradation by pyrolysis-gas chromatography, solid-state carbon-13 NMR, and Fourier-transform infrared spectroscopy. Macromolecules 1990, 23, 2460-2465. [CrossRef] 
101. Bajaj, P.; Sreekumar, T.V.; Sen, K. Thermal behaviour of acrylonitrile copolymers having methacrylic and itaconic acid comonomers. Polymer 2001, 42, 1707-1718. [CrossRef]

102. Zhu, Y.; Wilding, M.A.; Mukhopadhyay, S.K. Estimation, using infrared spectroscopy, of the cyclization of poly(acrylonitrile) during the stabilization stage of carbon fibre production. J. Mater. Sci. 1996, 31, 3831-3837. [CrossRef]

103. Krishnan, G.S.; Thomas, P.; Murali, N. Synthesis, characterization, and thermo-mechanical properties of poly(acrylonitrile-co-2,3-dimethyl-1,3-butadiene-co-itaconic acid) as carbon fibre polymer precursors. RSC Adv. 2016, 6, 6182-6190. [CrossRef]

104. Tsai, J.-S. Comparison of batch and continuous oxidation processes for producing carbon fibre based on PAN fibre. J. Mater. Sci. Lett. 1997, 16, 361-362. [CrossRef]

105. Tsai, J.-S. Orientation change for polyacrylonitrile precursor during oxidation. J. Mater. Sci. Lett. 1994, 13, 1162-1163. [CrossRef]

106. Mukhopadhyay, S.K.; Zhu, Y. Structure-Property Relationships of PAN Precursor Fibers During Thermo-oxidative Stabilization. Text. Res. J. 2016, 65, 25-31. [CrossRef]

107. Gupta, A.K.; Paliwal, D.K.; Bajaj, P. Effect of the nature and mole fraction of acidic comonomer on the stabilization of polyacrylonitrile. J. Appl. Polym. Sci. 1996, 59, 1819-1826. [CrossRef]

108. Gupta, A.K.; Paliwal, D.K.; Bajaj, P. Effect of an acidic comonomer on thermooxidative stabilization of polyacrylonitrile. J. Appl. Polym. Sci. 1995, 58, 1161-1174. [CrossRef]

109. Tsai, J.-S.; Lin, C.-H. Effect of comonomer composition on the properties of polyacrylonitrile precursor and resulting carbon fiber. J. Appl. Polym. Sci. 1991, 43, 679-685. [CrossRef]

110. Bhat, G.S.; Peebles, L.H.; Abhiraman, A.S.; Cook, F.L. Rapid stabilization of acrylic fibers using ammonia: Effect on structure and morphology. J. Appl. Polym. Sci. 1993, 49, 2207-2219. [CrossRef]

111. Zhao, J.; Zhang, J.; Zhou, T.; Liu, X.; Yuan, Q.; Zhang, A. New understanding on the reaction pathways of the polyacrylonitrile copolymer fiber pre-oxidation: Online tracking by two-dimensional correlation FTIR spectroscopy. RSC Adv. 2016, 6, 4397-4409. [CrossRef]

112. Fu, Z.; Ma, J.; Deng, Y.; Wu, G.; Cao, C.; Zhang, H. Structural evolution of poly(acrylonitrile-co-dimethyl itaconate) copolymer during thermal oxidative stabilization. Polym. Adv. Technol. 2015, 26, 322-329. [CrossRef]

113. Rahaman, M.S.A.; Ismail, A.F.; Mustafa, A. A review of heat treatment on polyacrylonitrile fiber. Polym. Degrad. Stab. 2007, 92, 1421-1432. [CrossRef]

114. Arbab, S.; Zeinolebadi, A. A procedure for precise determination of thermal stabilization reactions in carbon fiber precursors. Polym. Degrad. Stab. 2013, 98, 2537-2545. [CrossRef]

115. 115. Farsan, R.E.; Raissi, S.; Shokuhfar, A.; Sedghi, A. FT-IR Study of Stabilized PAN Fibers for Fabrication of Carbon Fibers. World Acad. Sci. Eng. Technol. 2009, 50, 430-433.

116. Hameed, N.; Sharp, J.; Nunna, S.; Creighton, C.; Magniez, K.; Jyotishkumar, P.; Salim, N.V.; Fox, B. Structural transformation of polyacrylonitrile fibers during stabilization and low temperature carbonization. Polym. Degrad. Stab. 2016, 128, 39-45. [CrossRef]

117. Socrates, G. Infrared and Raman Characteristic Group Frequencies Tables and Charts, 3rd ed.; John Wiley \& Sons, LTD: Middlesex, UK, 2001. [CrossRef]

118. Gulgunje, P.V.; Newcomb, B.A.; Gupta, K.; Chae, H.G.; Tsotsis, T.K.; Kumar, S. Low-density and high-modulus carbon fibers from polyacrylonitrile with honeycomb structure. Carbon 2015, 95, 710-714. [CrossRef]

119. Mathur, R.B.; Bahl, O.P.; Mittal, J. Advances in the development of high-performance carbon fibres from pan precursor. Compos. Sci. Technol. 1994, 51, 223-230. [CrossRef]

120. Chae, H.G.; Newcomb, B.A.; Gulgunje, P.V.; Liu, Y.; Gupta, K.K.; Kamath, M.G.; Lyons, K.M.; Ghoshal, S.; Pramanik, C.; Giannuzzi, L.; et al. High strength and high modulus carbon fibers. Carbon 2015, 93, 81-87. [CrossRef]

121. Chai, X.; Mi, H.; Zhu, C.; He, C.; Xu, J.; Zhou, X.; Liu, J. Low-temperature thermal stabilization of polyacrylontrile-based precursor fibers towards efficient preparation of carbon fibers with improved mechanical properties. Polymer 2015, 76, 131-139. [CrossRef]

122. Shin, H.K.; Park, M.; Kang, P.H.; Choi, H.-S.; Park, S.-J. Preparation and characterization of polyacrylonitrile-based carbon fibers produced by electron beam irradiation pretreatment. J. Ind. Eng. Chem. 2014, 20, 3789-3792. [CrossRef] 
123. Kim, S.Y.; Kim, S.-Y.; Choi, J.; Lee, S.; Jo, S.M.; Joo, J.; Lee, H.-S. Two step microwave plasma carbonization including low plasma power pre-carbonization for polyacrylonitrile based carbon fiber. Polymer 2015, 69, 123-128. [CrossRef]

124. Sung, M.-G.; Kawabata, Y. Strengthening of carbon fibers by a magnetic field imposed in the stabilization and carbonization process. Mater. Sci. Eng. A 2008, 488, 247-251. [CrossRef]

125. Xin, G.; Yao, T.; Sun, H.; Scott, S.M.; Shao, D.; Wang, G.; Lian, J. Highly thermally conductive and mechanically strong graphene fibers. Science 2015, 349, 1083-1087. [CrossRef]

126. Raghubanshi, H.; Dikio, E.D.; Naidoo, E.B. The properties and applications of helical carbon fibers and related materials: A review. J. Ind. Eng. Chem. 2016, 44, 23-42. [CrossRef]

127. Wu, G.-P.; Lu, C.-X.; Ling, L.-C.; Lu, Y.-G. Comparative investigation on the thermal degradation and stabilization of carbon fiber precursors. Polym. Bull. 2009, 62, 667-678. [CrossRef]

128. Xue, Y.; Liu, J.; Lian, F.; Liang, J. Effect of the oxygen-induced modification of polyacrylonitrile fibers during thermal-oxidative stabilization on the radial microcrystalline structure of the resulting carbon fibers. Polym. Degrad. Stab. 2013, 98, 2259-2267. [CrossRef]

129. Kim, S.Y.; Kim, S.Y.; Lee, S.; Jo, S.; Im, Y.H.; Lee, H.S. Microwave plasma carbonization for the fabrication of polyacrylonitrile-based carbon fiber. Polymer 2015, 56, 590-595. [CrossRef]

130. Liu, J.; Zhang, C.; Guo, S.; Xu, L.; Xiao, S.; Shen, Z. Microwave treatment of pre-oxidized fibers for improving their structure and mechanical properties. Ceram. Int. 2019, 45, 1379-1384. [CrossRef]

131. Korte, S. Physical Constants of Poly(acrylonitrile), 4th ed.; Brandrup, J., Immergut, E.H., Grulke, E.A., Eds.; John Wiley \& Sons, Inc.: New York, NY, USA, 1999.

132. Ji, B.H. Effect of Coagulation Bath Concentration on the Structure and Properties of Polyacrylonitrile as-Spun Fibers during Wet-Spinning. Adv. Mater. Res. 2011, 287, 1832-1836. [CrossRef]

133. Ouyang, Q.; Chen, Y.-S.; Zhang, N.; Mo, G.-M.; Li, D.-H.; Yan, Q. Effect of Jet Swell and Jet Stretch on the Structure of Wet-Spun Polyacrylonitrile Fiber. J. Macromol. Sci. Part B 2011, 50, 2417-2427. [CrossRef]

134. Ji, B.-H.; Wang, C.-G.; Wang, Y.-X. Effect of jet stretch on polyacrylonitrile as-spun fiber formation. J. Appl. Polym. Sci. 2007, 103, 3348-3352. [CrossRef]

135. Minagawa, M.; Yamada, H.; Yamaguchi, K.; Yoshii, F. Gamma-ray irradiation canal polymerization conditions ensuring highly stereoregular (>80\%) polyacrylonitrile. Macromolecules 1992, 25, 503-510. [CrossRef] 